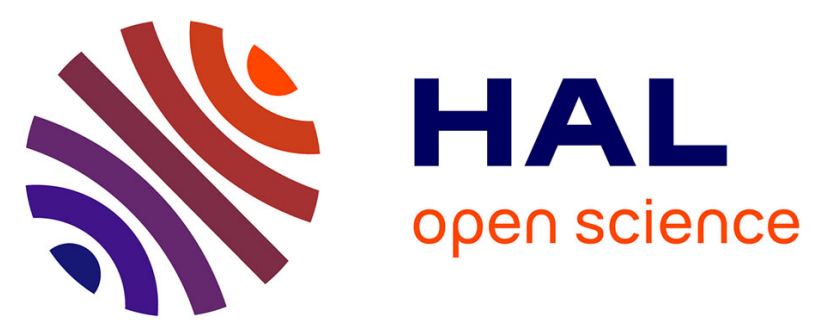

\title{
Conformation-dependent membrane permeabilization by neurotoxic PrP oligomers: The role of the $\mathrm{H} 2 \mathrm{H} 3$ oligomerization domain
}

Cécile Huin, Sabrina Cronier, Philippe Guégan, Vincent Béringue, Human Rezaei, Sylvie Noinville

\section{To cite this version:}

Cécile Huin, Sabrina Cronier, Philippe Guégan, Vincent Béringue, Human Rezaei, et al.. Conformation-dependent membrane permeabilization by neurotoxic $\operatorname{PrP}$ oligomers: The role of the $\mathrm{H} 2 \mathrm{H} 3$ oligomerization domain. Archives of Biochemistry and Biophysics, 2020, 692, 10.1016/j.abb.2020.108517 . hal-03064985

\section{HAL Id: hal-03064985 https://hal.science/hal-03064985}

Submitted on 4 Jan 2021

HAL is a multi-disciplinary open access archive for the deposit and dissemination of scientific research documents, whether they are published or not. The documents may come from teaching and research institutions in France or abroad, or from public or private research centers.
L'archive ouverte pluridisciplinaire HAL, est destinée au dépôt et à la diffusion de documents scientifiques de niveau recherche, publiés ou non, émanant des établissements d'enseignement et de recherche français ou étrangers, des laboratoires publics ou privés. 


\title{
Conformation-dependent membrane permeabilization by neurotoxic PrP oligomers: the role of the $\mathrm{H} 2 \mathrm{H3}$ oligomerization domain.
}

\author{
Cécile Huin ${ }^{1,2}$, Sabrina Cronier ${ }^{3}$, Philippe Guégan ${ }^{1}$, Vincent Beringue ${ }^{3}$, Human Rezaei ${ }^{3}$, \\ Sylvie Noinville ${ }^{3,4 *}$
}

${ }^{1}$ Sorbonne Universités, CNRS, Institut Parisien de Chimie Moléculaire, Equipe Chimie des Polymères, 4 place Jussieu, F-75005 Paris, France,

${ }^{2}$ University of Evry, F-91025 Evry, France,

${ }^{3}$ UR892, Virologie et Immunologie Moléculaires, Institut National de la Recherche Agronomique (INRA), Jouy-en-Josas, France.

${ }^{4}$ Sorbonne Universités, UPMC Univ Paris 06, CNRS, UMR8233, MONARIS, Université Pierre et Marie Curie, Paris, France.

*Corresponding author : Sylvie Noinville

Sorbonne Universités Laboratoire des Biomolécules, 4 place Jussieu, F-75005 Paris, France Telephone: (33) 144273 289; FAX: (33) 144273 021;

E-mail: sylvie.noinville@ sorbonne-universite.fr

\begin{abstract}
The relationship between prion propagation and the generation of neurotoxic species and clinical onset remains unclear. Several converging lines of evidence suggest that interactions with lipids promote various precursors to form aggregation-prone states that are involved in amyloid fibrils. Here, we compared the cytotoxicities of different soluble isolated oligomeric constructs from murine full-length $\mathrm{PrP}$ and from the restricted helical $\mathrm{H} 2 \mathrm{H} 3$ domain with their effects on lipid vesicles. The helical $\mathrm{H} 2 \mathrm{H} 3$ domain is suggested to be the minimal region of PrP involved in the oligomerization process. The discrete PrP oligomers of both the full-length sequence and the $\mathrm{H} 2 \mathrm{H} 3$ domain have de novo $\beta$-sheeted structure when interacting with the membrane. They were shown to permeabilize synthetic negatively charged vesicles in a dose-dependent manner. Restricting the polymerization domain of the full-length PrP to the $\mathrm{H} 2 \mathrm{H} 3$ helices strongly diminished the ability of the corresponding oligomers to associate with the lipid vesicles. Furthermore, the membrane impairment mechanism occurs differently for the fulllength PrP oligomers and the $\mathrm{H} 2 \mathrm{H} 3$ helices, as shown by dye-release and black lipid membrane experiments. The membrane damage caused by the full-length PrP oligomers is correlated to their neuronal toxicity at submicromolar concentrations, as shown by cell culture assays. Although oligomers of synthetic $\mathrm{H} 2 \mathrm{H} 3$ could compromise in vitro cell homeostasis, they followed a membrane-disruptive pattern that was different from the full-length oligomers, as revealed by the role of $\mathrm{PrP}^{\mathrm{C}}$ in cell viability assays.
\end{abstract}

Keywords: Prion, lipid-protein interaction, membrane, oligomer, conformational change, ion current, vesicle leakage, cell death. 


\section{INTRODUCTION}

It is now generally accepted that protein misfolding leading to aggregation is a key pathogenic feature of various amyloid-related disorders, including Alzheimer's disease, Parkinson's disease, Huntington's disease, type II diabetes, and prion diseases [1-3]. In prion diseases, the specific role of soluble oligomers, soluble protofibrils and mature fibrils in neurotoxicity and infectivity remains unknown $[4$, 5]. However, the early events that lead to the structural conversion of the prion protein $(\operatorname{PrP})^{1}$ appear to be related to the presence of more or less stable soluble oligomers, which might mediate neurotoxicity $[6,7]$. Considerable evidence now suggests that aggregation, toxicity, and infectivity are distinct properties of PrP that do not necessarily coincide. Several mutant forms of PrP that produce spontaneous neurodegeneration in humans and/or transgenic mice do not lead to the formation of infectious $\operatorname{PrP}^{\mathrm{Sc}}$ [8]. Previous findings also demonstrate that infectivity and toxicity are uncoupled in vivo [9]. Two distinct mechanistic phases take place in the development of prion diseases. The first phase consists of the autocatalytic production of infectivity up to a maximal prion titer, followed by a second phase of the production of neurotoxic species distinct from $\mathrm{PrP}^{\mathrm{Sc}}$.

It is widely accepted in the field of diseases associated with protein misfolding that oligomers or small fibrillar fragments are the most toxic species and are responsible for the impairment of cellular functions, whereas mature fibrils or plaques are considered innocuous or even protective [10-13]. Small soluble oligomers can be produced as prefibrillar intermediates on the pathway to mature amyloid fibrils [14, $15]$, as a result of fragmentation of mature fibrils or large aggregates [10,11], or as off-pathway products formed through alternative aggregation mechanisms [16].

Membrane disruption by amyloid oligomers is often considered to be a primary mechanism of toxicity in neurodegenerative disorders, but the mechanism by which these structures eventually cause neuronal cell dysfunction and death is not clearly understood [17]. Two mechanisms of neural dysfunction by membrane permeabilization have been recently proposed. The first argues that membrane permeabilization is induced by the formation of specific ion channels that may be inhibited by specific channel blockers [18-20]. The second mechanism suggests the involvement of nonspecific ion leakage $[21,22]$. One of the problems associated with these investigations is related to the fact that the oligomeric species are often unstable, making detailed structural analyses difficult [23].

In our previous works, we laid emphasis on the role of purified oligomers of the full-length and Nterminally truncated forms of PrP compared to the corresponding monomers on negatively charged vesicles $[24,25]$. Both oligomeric constructs possess the lipid-bound transmembrane domain $\operatorname{PrP}^{111-135}$, but this domain is differently accessible in the $\beta$-sheeted 12 -mers for membrane binding depending on the monomer primary sequence. Both the membrane leakage by the $\beta$-sheeted 12 -mers and the structural rearrangement of the lipid-bound oligomeric assembly suggest a pore-like mechanism. In a previous paper, the polymerization of the helical $\mathrm{H} 2 \mathrm{H} 3$ domain of ovine $\mathrm{PrP}$ was compared to that of the fulllength construct and found to also form two types of discrete soluble $\beta$-sheeted oligomers according to a parallel pathway [26, 27]. The two types of oligomers corresponded to off-pathway and on-pathway species, the latter leading to fibrillation. In the case of murine PrP, we showed that the oligomerization of $\mathrm{H} 2 \mathrm{H} 3$ is identical to the full-length sequence and gives exclusively 12-mers in a $\beta$-sheeted conformation in a stable manner due to the difference between the ovine and murine sequence at position 208 [28].

In the current work, we examined the role of the off-pathway oligomers from a murine sequence, which has the advantage to be isolated and purified and is more stable than the corresponding oligomers generated with the ovine sequence, which is more prone to aggregation [26]. In addition, in vitro experiments showed that negatively charged lipids accelerate the PrP aggregation [24, 29]. It is thus important to compare the membrane effect of the off-pathway oligomers produced in solution to the

\footnotetext{
${ }^{1}$ The abbreviations used are: $\operatorname{PrP}$, prion protein; $\operatorname{Pr}^{\mathrm{C}}$, cellular prion isoform; $\operatorname{Pr}^{\mathrm{Sc}}$, disease-associated scrapie isoform; mo-, mouse; DOPC, 1,2-dioleoyl-sn-glycero-3-phosphocholine; DOPS, 1,2-dioleoylsn-glycero-3-phospho-L-serine; ThT, thioflavin T; SLS, static light scattering; DLS, dynamic light scattering; L/P, Lipid/Protein; BLM, Black Lipid Membrane; iep, isoelectric point; SEC, size exclusion chromatography; $\mathrm{CGN}$, cerebellar granule neurons.
} 
distinct intermediates, if any, generated by the lipid-templated fibrillation. Another focus was to identify the minimal region in the prion protein sequence required for the formation of the discrete soluble oligomers to reach insights regarding the mechanism of oligomerization [28]. Here, the biophysical characterization of the stable 12-mers from the full-length murine $\mathrm{PrP}^{23-231}$ sequence (named $\mathrm{O}_{12} \mathrm{moPrP}$ ) and from the truncated moPrP $\mathrm{P}^{164-231}$ (named $\mathrm{O}_{12} \mathrm{moH} 2 \mathrm{H} 3$ ) are compared to decipher the effect of the $\mathrm{H} 2 \mathrm{H} 3$ polymerization domain on their ability to bind to model membranes. A phosphatidylcholine/phosphatidyl-serine lipid mixture has been used by several groups as a simplified mimic of mammalian neuronal cells [30-32]. In our study, we determined the binding affinities of the different constructs, either monomeric or oligomeric, towards lipid bilayers composed of DOPC/DOPS by FTIR-ATR experiments. Changes in the secondary structure of the proteins in contact with the planar lipid membrane were concomitantly compared to the free state in solution. The conformational changes were also studied in the presence of the lipid vesicles by circular dichroism. Static light scattering (SLS)ThT binding assays of the different oligomeric constructs interacting with DOPC/DOPS vesicles were compared to the corresponding monomers to determine the ThT-positive lipid-bound state of the different constructs. In addition to the use of well-defined discrete oligomers, this study encompassed structural and functional characterization to investigate the structure-membrane impairment relationship for the same lipid composition. The membrane impairment was determined by dye-release assays and BLM experiments, and the results are discussed in relation to neuronal toxicity. To characterize the toxic effect of different PrP conformations, we exposed primary neuronal cultures expressing or lacking cellular prion protein to submicromolar concentrations of exogenous oligomers $\left(\mathrm{O}_{12} \mathrm{moPrP}\right.$ and $\mathrm{O}_{12} \mathrm{moH} 2 \mathrm{H} 3$ ) and the corresponding monomers.

\section{MATERIAL AND METHODS}

\section{Materials}

DOPC (1,2-dioleoyl-sn-glycero-3-phosphocholine) and DOPS (1,2-dioleoyl-sn-glycero-3-phospho-Lserine) were purchased from Avanti-Polar, France. Triton-X-100 (Plus-One reagent) was obtained from Pharmacia biotech, Sweden. MOPS (4-morpholinepropanesulfonic acid), sodium citrate, triethylammonium acetate and sodium dodecyl sulphate (SDS) were purchased from VWR, France. Cholesterol, calcein, Thioflavin T (ThT), 8-anilino-1-naphthalene sulfonic acid (ANS), 3, [4,5 dimethylthiazol-2yl]-2,5 diphenyltetrazolium bromide (MTT) were purchased from Sigma-Aldrich, France.

\section{Expression of the PrP monomers and purification of the soluble oligomers of $\operatorname{PrP}$}

Murine full-length $\operatorname{PrP}^{23-231}(23 \mathrm{kDa})$, named moPrP, and the truncated domain $\operatorname{PrP}^{167-231}$, named $\mathrm{moH} 2 \mathrm{H} 3(7.7 \mathrm{kDa})$, were expressed recombinantly and purified as described [27, 33]. The soluble oligomers were obtained by incubation of the solution of moPrP or moH2 33 at a concentration of 80 $\mu \mathrm{M}$ in $20 \mathrm{mM}$ citrate buffer at $\mathrm{pH} 3.4$ and $50^{\circ} \mathrm{C}$ for $10 \mathrm{~min}$ in a Perkin Elmer GenAmp2400 thermocycler. The fraction corresponding to the 12-mer was collected in triethylammonium acetate buffer after separation by SEC using Akta FPLC and lyophilized before use as described previously [24].

\section{Preparation of the liposomes}

The DOPC/DOPS liposomes were prepared as follows. The amounts of DOPC:DOPS 80:20 mol/mol ratio, unless specified, were mixed in chloroform. Solutions of the lipid mixtures were dried under vacuum, until the lipids formed a thin layer inside the flask. The lipid films were then suspended in the desired buffer at a total lipid concentration of $2 \mathrm{mg} / \mathrm{mL}$. The resulting suspension was freeze-thawed three times before extrusion using a Northern lipids apparatus (Vancouver, Canada) through two stacked $0.1 \mu \mathrm{m}$ polycarbonate filters (Millipore, France) to obtain unilamellar vesicles. The liposome suspension was prepared freshly for each experiment, and the size of the liposomes was confirmed using DLS. The suspensions were monodisperse, with mean hydrodynamic diameters of $110 \mathrm{~nm} \pm 10 \mathrm{~nm}$. 


\section{Dynamic Light Scattering}

The sizes of the different prepared liposomes were measured at $18^{\circ} \mathrm{C}$ using a Malvern nanosizer ZS (Malvern Instruments, France) containing a temperature controlled sampler unit to investigate possible aggregation after addition of the monomer or oligomer solutions. The lipid concentration of the DLS samples was $125 \mu \mathrm{M}$, unless specified and the protein concentrations were adjusted such that the same lipid-to-protein molar ratio was used as for the dye-release assays.

\section{SLS-Thioflavin T Fluorescence Correlation Experiments}

The combined SLS-fluorescence kinetics experiments were performed on a homemade device using a 407-nm laser beam for the excitation of ThT and three other lasers $(473,533$, and $633 \mathrm{~nm})$ for light scattering measurements as described previously [27]. Stock solutions of ThT were prepared in MOPS buffer to a final concentration of $3 \mathrm{mM}$, and the concentration was determined using a molar extinction coefficient of $24,420 \mathrm{M}^{-1} \mathrm{~cm}^{-1}$ at $420 \mathrm{~nm}$. This solution was then filtered on a $0.2 \mu \mathrm{m}$ pore-sized filter. Liposomes of DOPC:DOPS $85: 15 \mathrm{~mol} / \mathrm{mol}$ ratio were incubated at $25{ }^{\circ} \mathrm{C}$ in a $2-\mathrm{mm}$ cuvette in the presence of $100 \mu \mathrm{M}$ ThT before addition of oligomeric or monomeric protein samples (at a final concentration of $1-5 \mu \mathrm{M}$ ) in $20 \mathrm{mM}$ MOPS at $\mathrm{pH}$ 6.8. The fluorescence at $485 \mathrm{~nm}$ and light scattered signals were recorded at a $112^{\circ}$ angle. Signal processing was achieved by a homemade MatLab program. The experiments were performed in two independent manners. A representative plot was shown for each species.

\section{The dye-entrapped liposomes assays}

Calcein-entrapped liposomes were prepared according to the procedures described above. Calcein was dissolved in $10 \mathrm{mM}$ MOPS and $100 \mathrm{mM} \mathrm{KCl}$ at $\mathrm{pH} 7$ by repeated vortexing for $30 \mathrm{~min}$ at room temperature, to a final concentration of $80 \mathrm{mM}$. The chloroform solution containing $5 \mathrm{mg}$ of total lipid of DOPC:DOPS $85: 15 \mathrm{~mol} / \mathrm{mol}$ ratio was evaporated under nitrogen and resuspended in calcein solution. The resulting mixture was passed after extrusion through a Sephadex-G25 column (Amersham Biosciences) in the desired buffer, to remove the non-entrapped dye. The suspensions of calceinentrapped vesicles were monodisperse, and their mean size, as measured by DLS, was $110 \mathrm{~nm} \pm 15 \mathrm{~nm}$. An increase in the fluorescence intensity of the dye-entrapped liposomes after incubation with monomers or oligomers of $\operatorname{PrP}$ constructs indicated a protein-induced liposomal leakage. The experiments were run at $18^{\circ} \mathrm{C}$ in a $2 \times 10 \mathrm{~mm}$ quartz cuvette. Briefly, concentrated protein samples were diluted in a suspension of vesicles in $10 \mathrm{mM}$ MOPS and $100 \mathrm{mM} \mathrm{KCl}$ at $\mathrm{pH}$ 7. The medium was stirred continuously to allow rapid mixing of the protein and vesicles. The samples were excited at $492 \mathrm{~nm}$, and their emission was recorded at $520 \mathrm{~nm}$, using a Jasco FP-777 spectrofluorimeter. The total release of calcein was achieved by the addition of Triton X-100 at a final concentration of $0.05 \%(\mathrm{v} / \mathrm{v})$ at the end of each titration series, so that the maximum fluorescence intensity could be determined. The percent leakage value was determined at 5 minutes of interaction with lipid vesicles, and calculated according to previously described procedures [24]. The experimental results were expressed as mean \pm SD of at least two independent experiments.

\section{Black Lipid Membrane (BLM) Measurements}

The planar lipid bilayers were prepared as follows. A solution of a lipid mixture DOPC:DOPS 80:20 $\mathrm{mol} / \mathrm{mol}$ ratio in chloroform was dried under vacuum, until the lipids formed a thin layer on the flask wall. The lipid films were then suspended in decane at a total lipid concentration of $4 \mathrm{mg} \cdot \mathrm{mL}^{-1}$. A film of DOPC/DOPS was then spread across a $150 \mu \mathrm{m}$ wide hole, separating two chambers of the measurement device (Harvard Apparatus). Each chamber contained $1 \mathrm{~mL}$ of MOPS buffer solution containing $\mathrm{KCl} 150 \mathrm{mM}$, at $\mathrm{pH}$ 6.8. After thinning the film and obtaining a planar bilayer of appropriate capacitance (at least $35 \mathrm{pF}$ ), solutions of monomers or oligomers were added in both chambers at a controlled concentration. A voltage was then applied to the lipid bilayer and current measurements were performed. The ion current through the membrane was measured with an Axopatch 200B (Axon, 
Molecular Devices). Data were acquired at $100 \mathrm{kHz}$ and filtered at $10 \mathrm{kHz}$ with the Measurement Computing Digitizer and analyzed as previously described [34]. The experiments were repeated three times and a representative trace was shown in Figure 2.

\section{FTIR spectral acquisition and PrP adsorption kinetics on lipid bilayers}

Infrared analysis of lipid-bound protein was conducted using a Bruker 55 spectrometer equipped with a mercury cadmium telluride detector, continuously purged with dry air. A $45^{\circ}$ cut silicon plate mounted in an ATR liquid cell was used as the multiple internal reflections element, providing 30 useful internal reflections at the buffer/silicon interface. FTIR-ATR spectra were recorded using a boxcar apodization at $4 \mathrm{~cm}^{-1}$ resolution with 128 scans being averaged. A supported lipid bilayer was formed by the spontaneous fusion of DOPC/DOPS vesicles onto the freshly cleaned silicon ATR element [35]. The deuterated buffer used was $10 \mathrm{mM}$ MOPS, $150 \mathrm{mM} \mathrm{NaCl}$ in $\mathrm{D}_{2} \mathrm{O}$, adjusted to $\mathrm{pD} 7.4$ by the addition of DCl. The cell was then filled with the suspensions of DOPC/DOPS vesicles diluted to $0.1 \mathrm{mg} / \mathrm{mL}$ in the deuterated buffer containing $2 \mathrm{mM} \mathrm{CaCl} 2$. After 30 min of contact, the cell was rinsed with $20 \mathrm{mM}$ MOPS buffer in $\mathrm{D}_{2} \mathrm{O}$ at $\mathrm{pD} 6.8$ to ensure the removal of lipid vesicles in excess and check the amount of lipid deposited corresponding to the single lipid bilayer. A reference IR spectrum was collected before filling the cell with the protein solution in the deuterated buffer at $\mathrm{pD}$ 6.8. The zero time-point for the adsorption kinetics was set to time at the start of filling the ATR cell with the protein solution. IR spectra were recorded as for the last reference spectrum and transformed to the absorption spectra of the adsorbed protein. The integrated absorbance of the Amide I' band was used to determine the amount of moPrP or moH2 33 species adsorbed onto the planar lipid bilayers in stationary conditions as previously described [24]. The experiments were performed in two independent manners.

\section{Semi-Quantitative analysis of adsorbed protein secondary structure}

The broad Amide I' band in the spectral range from $1600-1700 \mathrm{~cm}^{-1}$ is assigned to peptide carbonyl stretching modes, and it reveals the extent of the secondary structure of the protein. Spectral decomposition with the aid of a second derivative analysis was suitable for both the free and adsorbed moPrP or moH2 33 and was performed from the Amide I' band analysis, such that the extent of the different types of secondary structures could be compared directly for the protein in solution or in the lipid-bound state depending on the oligomeric or monomeric states (see Supplemental information, Table S1). Prior to spectral decomposition, the baseline was done between 1500 and $1750 \mathrm{~cm}^{-1}$. The curve-fittings were performed on the $1500-1750 \mathrm{~cm}^{-1}$ spectral region by taking into account the characteristic infrared bands due to vibrational modes of the Tyr side-chains $\left(1515 \mathrm{~cm}^{-1}\right)$, the Amide II modes $\left(1530-1550 \mathrm{~cm}^{-1}\right)$, the Asp and Glu side-chains $\left(1565-1585 \mathrm{~cm}^{-1}\right)$, the $\mathrm{C}=\mathrm{C}$ stretching mode of the aromatic side chains $\left(1595-1608 \mathrm{~cm}^{-1}\right)$ and the Amide I' bands $\left(1615-1700 \mathrm{~cm}^{-1}\right)$, as previously reported [36]. The spectral decomposition was performed using the least-square iterative curve-fitting program (Origin) with fixed component band positions and profiles for each species. The accuracy of the spectral decomposition analysis was determined by calculating standard errors from three different curve fittings using one spectrum over the overall spectra as a reference model. The component bands were assigned according to our previous work $[24,25,36]$ and according to the infrared analysis of $\beta$ structured or $\beta$-aggregated proteins $[37,38]$.

\section{Circular Dichroism Measurements}

Circular Dichroism (CD) spectra were obtained with a Jasco J-810 spectropolarimeter. Spectra were recorded using a $1-\mathrm{mm}$ path length cuvette, scanning from 250 to $190 \mathrm{~nm}$ with a step size of $0.2 \mathrm{~nm}$ and a scanning speed of $20 \mathrm{~nm} / \mathrm{min}$. The CD spectra represented averages of 8 scans and the CD spectra of the lipid-protein suspensions were recorded after 5 minutes of incubation with the lipid vesicles of DOPC:DOPS $85: 15 \mathrm{~mol} / \mathrm{mol}$ ratio, and were corrected by subtraction of the contribution of the pure lipid suspension. Thus the data in Figure 2 represent the $C D$ signal originating from the proteins only.

\section{Transgenic Mouse lines}


Care of mice was performed according to institutional and national animal care committee guidelines (Comethea Permit number 12/034). To ensure a consistent genetic background, primary neuronal cultures were derived from the following homozygous transgenic mouse lines: $\operatorname{PrP}^{0 / 0}$ (PrP knock-out mice) (Zurich I [39]), and Zurich I-derived tga20 (mouse Prnp- $a$ allele [40]).

\section{Primary mouse cerebellar cultures}

Primary cultures of cerebellar granule neurons (CGN) were established as previously described [41, 42]. Briefly, CGN extracted from P6 cerebellum by enzymatic and mechanical dissociation were plated (250 000 cells/well) in 48 -well plates coated with poly-D-lysine $(20 \mu \mathrm{g} / \mathrm{ml}$, Sigma). CGN cultures were maintained at $37^{\circ} \mathrm{C}$ with $6 \% \mathrm{CO}_{2}$ in Dulbecco's modified Eagle's medium (DMEM) containing ultraglutamine (BioWhittaker), 10\% fetal calf serum (FCS, BioWhittaker), $20 \mathrm{mM} \mathrm{KCl}$, penicillin, streptomycin (Gibco) and complemented with N2 and antioxidant-depleted B27 supplements (Gibco).

\section{In vitro neurotoxicity experiments}

After 7 days in culture, neurons were incubated for $72 \mathrm{~h}$ with the different recombinant PrP proteins resuspended in MOPS buffer (10 $\mathrm{mM} \mathrm{pH} \mathrm{6.8).} \mathrm{To} \mathrm{ensure} \mathrm{uniformity} \mathrm{among} \mathrm{wells,} \mathrm{volumes} \mathrm{of} \mathrm{culture}$ medium were adjusted to $300 \mu \mathrm{l} /$ well before PrP addition and 5 to $10 \mu \mathrm{l}$ of recombinant protein solution was added to quadruplicate wells. For controls, the cells were exposed to an equivalent volume of buffer solution ('mock treatment').

After exposure of neurons to the proteins, the viability was measured with the MTT assay. A $4 \mathrm{mg} / \mathrm{ml}$ solution of MTT dissolved in PBS was diluted 10-fold in culture medium. After $2 \mathrm{~h}$ of incubation at $37^{\circ} \mathrm{C}$ in the dark, the culture medium was removed and the blue formazan was solubilized with an isopropanol/HCl $1 \mathrm{~N}(92: 8)$ solution. Samples were immediately transferred to a 96-well plate and optical density was measured at $550 \mathrm{~nm}$ on the Multiskan FC microplate photometer (Thermo Scientific). Plate background value was subsequently subtracted from all samples for each experiment. Neuronal survival is expressed as a percentage of total living neurons (NeuN-positive cells) in mocktreated cultures. Analysis of statistical significance was done using Mann-Whitney U-test. Statistical analysis data were expressed as means \pm SE of four independent experiments $(n=4)$.

\section{RESULTS}

\section{In vitro membrane leakage}

The ability of moPrP and $\mathrm{H} 2 \mathrm{H} 3$, either in monomeric or oligomeric forms, to disrupt phospholipid membranes of DOPC/DOPS was examined by dye-release and BLM experiments.

The monomers of both moH2H3 and moPrP showed lytic activity towards DOPC/DOPS vesicles but only reached $20 \%$ and $25 \%$, respectively, of the dye content at a concentration of $500 \mathrm{nM}$ (Fig $1 \mathrm{~A}$ and 1C). While moH2H3 did not significantly perturb the size distribution of the lipid vesicles (Fig S1), moPrP induced aggregation of the negatively charged vesicles at the corresponding lipid/protein (L/P) molar ratio of 250/1, as shown by DLS experiments (Fig S2). Most intriguing, the monomeric moH2H3 had the same lytic activity as the monomeric moPrP but did not cause the aggregation of the liposomes, suggesting a different mechanism of leakage. As shown by the BLM experiments, no moPrP-lipid bilayer interaction was detected in the presence of moPrP monomers in the 68 to $272 \mathrm{nM}$ range (Fig 2C and $3 \mathrm{C}$ ), while the moH2 33 monomer caused membrane disruption after $40 \mathrm{~s}$ at a concentration of 280 $\mathrm{nM}$ at an applied voltage of $+100 \mathrm{mV}$ (Fig 2A). The histogram of occurrence, giving the number of data points plotted as a function of current, allowed us to observe well-defined jumps for the monomeric $\mathrm{moH} 2 \mathrm{H} 3$ (Fig 3A and 3A1), with an average unitary current estimated as $17.5 \mathrm{pA}$ at an applied voltage of $+100 \mathrm{mV}$. These results corroborate a mode of interaction of moH2H3 with lipids that is different from that of the full-length protein. 
When moPrP oligomers were added to DOPC/DOPS vesicles, a drastic release of calcein was detected by the dye-release experiments in a manner dependent on the $\mathrm{L} / \mathrm{P}$ ratio (Figure 1D). At low concentrations, below $100 \mathrm{nM}$ of $\mathrm{O}_{12} \mathrm{moPrP}$, the dye release reached $65 \%$ at a lipid concentration of $62.5 \mu \mathrm{M}$. It decreased to $40 \%$ at $125 \mu \mathrm{M}$ and to only $22 \%$ at $250 \mu \mathrm{M}$, thus indicating a high affinity for the DOPC/DOPS membrane (Fig 1D). For a L/P molar ratio in the range 62.5/1 to 250/1, the leakage reached $60 \%$ for an $\mathrm{O}_{12} \mathrm{moPrP}$ concentration of $500 \mathrm{nM}$ compared to $20 \%$ for the monomer at the equivalent concentration (Fig 1B).

The high binding of moPrP oligomers to DOPC/DOPS was confirmed by the rapid disruption of the membrane, which occurred after $50 \mathrm{~s}$ at a concentration of $30 \mathrm{nM}$ at $+100 \mathrm{mV}$ (data not shown). A too fast diffusion of the positively charged oligomers towards the lipid bilayer was suspected. A voltage of $+50 \mathrm{mV}$ was then applied to study the interaction of the moPrP oligomers with the model lipid membrane (Fig 2D). $\mathrm{O}_{12} \mathrm{moPrP}$ was added to both chambers from $3 \mathrm{nM}$ to $30 \mathrm{nM}$, and current versus time was recorded to document events or interactions. Discrete intensity increase/decrease was observed at a concentration of $30 \mathrm{nM} \mathrm{O}{ }_{12} \mathrm{moPrP}$ before the disruption of the membrane, which was at $500 \mathrm{~s}$ (Fig 2D). The histogram of occurrence revealed a set of peaks between 0 and $40 \mathrm{pA}$ (Fig 3D and 3D1) at a constant intensity gap, confirming the presence of well-defined permeation structures attributed to pore formation in the lipid bilayers that was induced by the moPrP oligomers. The unitary current was estimated at $20 \mathrm{pA}$ for an applied voltage of $+50 \mathrm{mV}$.

In contrast to the oligomers of full-length moPrP, the oligomers formed by the $\mathrm{H} 2 \mathrm{H} 3$ domain had no significant effect on calcein release at low concentrations (between 10 to $500 \mathrm{nM}$ ), and the dye release reached $15 \%$ of the dye content at concentrations above $800 \mathrm{nM}$ at a lipid concentration of $125 \mu \mathrm{M}$ (Fig 1A). When $\mathrm{O}_{12} \mathrm{moH} 2 \mathrm{H} 3$ was added at concentrations ranging from 10 to $60 \mathrm{nM}$ to DOPC/DOPS bilayers at $+100 \mathrm{mV}$, interactions were observed and disruption of the membrane occurred after $100 \mathrm{~s}$ (at $60 \mathrm{nM}$ ) (Fig 2B). The data analysis showed a steady decrease of events versus intensity without any identifiable peak in the 0-1200 pA range (Fig 3B), suggesting that the interaction between moH2H3 oligomers and the model lipid membrane was achieved via a mechanism of leakage different from that of the moPrP oligomers.

\section{DOPC/DOPS membranes induce a $\beta$-structured conformation of monomeric moPrP and moH2H3}

To determine the structural basis for the lytic activities of the monomeric species, we analyzed the CD and FTIR spectra of the monomeric proteins in the presence or absence of DOPC/DOPS lipids. The CD spectra of monomeric H2H3 (Fig 4A) and monomeric moPrP (Fig 4C) in MOPS buffer exhibited a strong minimum at $208 \mathrm{~nm}$ and a weaker minimum at $222 \mathrm{~nm}$, indicating an $\alpha$-helical structure. In the presence of DOPC/DOPS vesicles, the CD spectra of both monomeric moPrP and moH2H3 exhibited a strong CD minimum at $220 \mathrm{~nm}$ and a weaker minimum at $208 \mathrm{~nm}$ in a lipid concentration-dependent manner. These CD spectra were suggestive of a de novo $\alpha / \beta$ conformation [43]. It should be noted that if only a fraction of the proteins bound to lipid membranes, the CD signal around $208 \mathrm{~nm}$ was attributable to free proteins in the buffer. To ascertain the conformational change of the proteins bound to the lipid membranes, the monomers were added to supported lipid bilayers and characterized by surface-sensitive ATR-FTIR spectroscopy. Figure 5A shows strong binding of the monomeric moPrP in $\alpha$-helical form to the DOPC/DOPS bilayer. This binding caused the unfolding of polar and apolar $\alpha$-helices, as indicated by the decrease in the respective IR component bands at 1650 and $1665 \mathrm{~cm}^{-1}$, giving rise to intermolecular and intramolecular $\beta$-sheets in the lipid-bound state of moPrP, corresponding to the increase in the component bands at 1614 and $1630 \mathrm{~cm}^{-1}$, respectively (Fig 5C and Table S1). The monomeric $\mathrm{moH} 2 \mathrm{H} 3$, with an isoelectric point (iep) of 5.5, is weakly negatively charged at pD 6.8 (scheme 1), and the binding of moH2H3 to DOPC/DOPS bilayer is weaker than for the full-length moPrP (Fig 5B). However, a strong conformational change of the mainly $\alpha$-helical monomeric moH2H3 occurred after $30 \mathrm{~min}$ of contact with the lipid bilayer (Fig 5B, D). The drastic unfolding of $\mathrm{moH} 2 \mathrm{H} 3$ $\alpha$-helices involved $20 \%$ of the moH2 33 polypeptide backbone and mainly corresponded to the formation of intermolecular $\beta$-sheets (absorbing at $1614 \mathrm{~cm}^{-1}$ ) present in the lipid-bound state. From 30 
min to 90 min of moH2H3 adsorption onto DOPC/DOPS, the decrease in intermolecular $\beta$-sheet, corresponding to the component band at $1614 \mathrm{~cm}^{-1}$, was concomitant with increased moH2H3 binding, suggesting that the subsequently adsorbed $\mathrm{moH} 2 \mathrm{H} 3$ monomers were less altered by the lipid environment (Fig 5D). SLS and ThT binding kinetic profiles of the lipid-induced fibrillation are shown for moPrP added to DOPC/DOPS vesicles (Fig 6A, 6B). The intensity at $633 \mathrm{~nm}$ increased immediately after the addition of monomeric moPrP to the vesicle suspension, then decreased from 1 to 8 min and then increased again from 8 to $60 \mathrm{~min}$, following a sigmoidal shape. The SLS curve indicated two phenomena: (i) rapid moPrP binding leads to membrane disruption, as revealed by the dye-release assays, resulting in decreased intensity at $633 \mathrm{~nm}$; and (ii) ongoing moPrP binding due to strong electrostatic interactions between positively charged monomers and negatively charged lipid membranes entails moPrP polymerization as well as lipid aggregation, as shown by DLS (Fig S2B). The increased ThT intensity from 8 to 60 min concomitant with the sigmoidal increase in intensity at 633 $\mathrm{nm}$ (Fig 6A) corresponded to the presence of lipid-bound $\beta$-sheeted intermediates, as shown by CD (Fig 4C) and FTIR (Fig 5C).

Compared to the full-length monomeric PrP, binding of monomeric moH2H3 to the DOPC/DOPS vesicles did not produce vesicle aggregation at similar L/P ratios (Fig 6C) or a significant increase in ThT binding (Fig 6D). The CD spectrum of $\mathrm{moH} 2 \mathrm{H} 3$ in the presence of DOPC/DOPS vesicles, showing de novo $\alpha / \beta$ conformation (Fig 4A), certainly contained some contribution of the unbound $\alpha$-helical monomers present in the buffer, as shown by the reduced binding of $\mathrm{moH} 2 \mathrm{H} 3$ to the lipid bilayer (Fig 5B). The lipid-bound state of $\mathrm{moH} 2 \mathrm{H} 3$ as determined by FTIR analysis contained a high fraction of intermolecular $\beta$-sheet absorbing at $1616 \mathrm{~cm}^{-1}$ and intramolecular $\beta$-sheet at $1630 \mathrm{~cm}^{-1}$ (Fig 5D) and (Table S1). However, this aforementioned conformational state of moH2H3 showed low ThT binding (Fig 6D). The kinetic profiles of monomers binding to DOPC/DOPS vesicles showed that only fulllength moPrP led to intermediate states with higher ThT binding (Fig 6B).

\section{The modified $\beta$-sheeted conformations of oligomers induced by DOPC/DOPS membranes are ThT positive}

The binding to lipid bilayers as well as the changes in secondary structure over time for $\mathrm{O}_{12} \mathrm{moH} 2 \mathrm{H} 3$ and $\mathrm{O}_{12} \mathrm{moPrP}$ are shown in Figure 7. Compared to the respective monomers, the oligomers presented S-shaped adsorption kinetics patterns upon binding to the DOPC/DOPS lipid bilayers. For both oligomeric constructs, the adsorption to lipid bilayers caused a change in the $\beta$-structure of the solvated oligomers (Fig 7C, 7D). From the Amide I' analysis, $28 \%$ of $\mathrm{O}_{12} \mathrm{moH} 2 \mathrm{H} 3$ was composed of the polypeptide backbone in intramolecular $\beta$-sheets absorbing at $1620 \mathrm{~cm}^{-1}$ and $28 \%$ absorbing at $1638 \mathrm{~cm}^{-}$ ${ }^{1}$ (Figure S3; Table S1). The former component band is attributable to $\beta$-sheets that have either a more planar conformation [44] or are composed of a larger number of strands [45]. Upon binding to the lipid membrane, the $\beta$-structure of $\mathrm{O}_{12} \mathrm{moH} 2 \mathrm{H} 3$ was altered by increasing the domains with more planar $\beta$ sheets $\left(1620 \mathrm{~cm}^{-1}\right)$ at the expense of regular $\beta$-sheets $\left(1638 \mathrm{~cm}^{-1}\right)$. In solution, the full-length oligomers had a larger content (27\%) of $\beta$-turns, generally assigned to the component band at $1665 \mathrm{~cm}^{-1}$, compared to $14 \%$ for $\mathrm{O}_{12} \mathrm{moH} 2 \mathrm{H} 3$. The $\mathrm{O}_{12} \mathrm{moPrP}$ also contained $25 \%$ of intramolecular $\beta$-sheets at $1622 \mathrm{~cm}^{-1}$ and $22 \%$ at $1638 \mathrm{~cm}^{-1}$. Once adsorbed onto the lipid bilayer, $\mathrm{O}_{12} \mathrm{moPrP}$ lost the domains absorbing at 1665 $\mathrm{cm}^{-1}$ and formed new intramolecular $\beta$-sheets at $1622 \mathrm{~cm}^{-1}$, along with random domains at $1650 \mathrm{~cm}^{-1}$ (Table S1). The changes in $\beta$-structure were also confirmed in the presence of vesicles by $C D$ measurements. The CD spectra of both $\mathrm{O}_{12} \mathrm{moH} 2 \mathrm{H} 3$ and $\mathrm{O}_{12} \mathrm{moPrP}$ exhibited strong minimums at 217 $\mathrm{nm}$ and $219 \mathrm{~nm}$, respectively, indicating a $\beta$-sheeted conformation in solution (Fig 4B and 4D); this finding is in agreement with the IR analysis (Figure S3). In the presence of DOPC/DOPS vesicles, the intensity of the minimum decreased for both species but to a lesser extent than for the full-length protein. The decreased signal at $218 \mathrm{~nm}$ could be from light scattering due to the increased size of the oligomervesicles complex, as also shown by the increased intensity at $633 \mathrm{~nm}$ measured by SLS for the fulllength and truncated oligomers (Fig 8A and 8C). Figures 8B and 8D respectively show the ThT binding of the oligomeric moPrP and moH2H3 when bound to DOPC/DOPS vesicles. The change in ThT intensity was immediate after the addition of oligomers to the DOPC/DOPS suspension and remained constant for 1 hour. For $\mathrm{O}_{12} \mathrm{moPrP}$, the ThT intensity increased from 0.75 to 1 in the presence of 
DOPC/DOPS, while the pure oligomer at a concentration of $2 \mu \mathrm{M}$ gave an intensity of 0.83 . For $\mathrm{O}_{12} \mathrm{moH} 2 \mathrm{H} 3$, the increased ThT signal was 0.92 at $5 \mathrm{~min}$ compared to a reference value of 0.79 for a solution of $5 \mu \mathrm{M}$ pure moH2H3 oligomer and reached 0.97 after 1 hour of incubation with DOPC/DOPS vesicles. In a previous study, we showed that moH2H3 oligomers have poor affinity for ThT [46]. Nevertheless, the increase in ThT binding of lipid-bound $\mathrm{O}_{12} \mathrm{moH} 2 \mathrm{H} 3$ occurred spontaneously and was linked to the increase in the component band at $1665 \mathrm{~cm}^{-1}$, as indicated in Fig 7D. According to other studies [47, 48], a more twisted or less stacked $\beta$-structure conformation also explains the appearance of the IR component band at $1665 \mathrm{~cm}^{-1}$. We suggest that a less stacked $\beta$-structure would favor ThT binding. In addition, the full-length oligomers in solution present a larger content of less stacked $\beta$ structure $\left(1665 \mathrm{~cm}^{-1}\right)$, corroborating the higher ThT binding of full-length oligomers compared to $\mathrm{O}_{12} \mathrm{moH} 2 \mathrm{H} 3$. Both oligomers in their lipid-bound state are in a $\beta$-sheeted conformation, with higher ThT affinities, suggesting a rapid lipid-induced conformational change.

\section{Cell viability assays}

Differentiated cerebellar granule neurons expressing homologous $\operatorname{PrP}^{\mathrm{C}}\left(\mathrm{CGN}^{20}\right)$ or not $\left(\mathrm{CGN}^{0 / 0}\right)$ were exposed for $72 \mathrm{~h}$ to either monomeric or oligomeric full-length moPrP or moH2H3 at two submicromolar concentrations. Their viability was examined by MTT assay as shown in Figure 9. The most important finding was that oligomers of the full-length $\mathrm{PrP}$ and of the $\mathrm{H} 2 \mathrm{H} 3$ sequence exhibited significant cytotoxicity for neurons devoid of $\mathrm{PrP}^{\mathrm{C}}$ at the submicromolar concentrations tested. There was a loss of approximately $20 \%$ of the neurons compared to control cells treated with the monomers. Notably, neurons devoid of $\mathrm{PrP}^{\mathrm{C}}$ are reportedly more sensitive to neurotoxins [49]. At the $50 \mathrm{nM}$ dose, the moPrP oligomers were neurotoxic for both $\mathrm{CGN}^{0 / 0}$ and $\mathrm{CGN}^{20}$, whereas $\mathrm{O}_{12} \mathrm{moH} 2 \mathrm{H} 3$ was neurotoxic for $\mathrm{CGN}^{0 / 0}$ but not for $\mathrm{CGN}^{20}$, suggesting a different requirement for PrP expression in mediating their toxicity. At the $100 \mathrm{nM}$ concentration, the toxic effect of $\mathrm{O}_{12} \mathrm{moH} 2 \mathrm{H} 3$ was statistically significant in $\mathrm{CGN}^{20}$ as compared to $\mathrm{moH}_{2} \mathrm{H}_{3}$ (Figure 9D).

\section{DISCUSSION}

\section{Link between lipid-bound conformational states of monomers and membrane impairment}

Since the lipid membrane could act as a template for $\beta$-aggregation, it was important to determine the conformational states responsible for the membrane impairment. In contrast to the full-length monomer, monomeric $\mathrm{moH} 2 \mathrm{H} 3$ produces dye release at high concentrations without leading to liposome aggregation, as shown by the DLS experiments (Figure S1A). The different modes of action of moH2H3 and full-length PrP towards the lipid membrane was also corroborated by the BLM technique. The ability of $\mathrm{moH} 2 \mathrm{H} 3$ to produce ion channels with stepwise ion currents indicates the existence of welldefined lipid-bound structures that destabilize the lipid bilayers (Scheme 1). Although moH2H3 with an iep of 5.5 is overall weakly negatively charged at $\mathrm{pD} 6.8$, binding to the negatively charged lipid bilayer still occurs and induces a large conformational change from $\alpha$-helical to $\beta$-sheeted structure. Such unfavorable adsorption of the charged protein surface is known to occur via an entropic mechanism [50]. To minimize its energy in the vicinity of the hydrophobic lipid bilayer, the adsorbed moH2 $\mathrm{H} 3$ is compelled to rearrange its conformational structure by exposing the hydrophobic residues that were previously involved in internal interactions for $\alpha$-hairpin stabilization to the external lipid surface. Many studies have used MD simulations to show that the residues corresponding to $\mathrm{H} 2$ unfold first, and then those in $\mathrm{H} 3$ are replaced by newly formed $\beta$-sheets in ovine or murine PrP sequences [51, 52]. The large conformational change from $\alpha$ - to $\beta$-sheet that moH2H3 undergoes in the presence of the lipid bilayer leads to the channel-forming lipid-bound state containing a high fraction of intermolecular $\beta$-sheets, as shown by the surface-sensitive FTIR-ATR experiments. The infrared component band absorbing at 1616 $\mathrm{cm}^{-1}$ was generally assigned to intermolecularly $\mathrm{H}$-bonded $\beta$-sheets, and its presence indicates that the lipid-bound state is no longer in a monomeric state. It should be noticed that the IR signal could result from different conformers coexisting at the buffer/membrane interface. Surprisingly, the lipid-bound 
state of moH2H3 has low ThT binding, suggesting that the membrane-active structures are not an amyloid structure. Of note, many studies have demonstrated the difference in ThT binding of amyloidogenic proteins with distinct patterns of fibrillation [53]. Thus, it is not surprising that the conformation of the lipid-bound $\mathrm{moH} 2 \mathrm{H} 3$ enriched in $\beta$-structure can present a poor affinity for the ThT probe that is generally used for detection of cross-beta structure.

MoPrP monomers also induced low membrane leakage that was similar to the moH2 $\mathrm{H} 3$ constructs at corresponding concentrations. However, in contrast with $\mathrm{moH} 2 \mathrm{H} 3$, moPrP monomers caused vesicle aggregation (Figure S2). Nevertheless, the difference in terms of vesicle aggregation induced by monomers could be interpreted as protein-protein rather than protein-lipid interactions. Indeed, formation of protein clusters at lipid membrane in presence of the $\mathrm{N}$-terminal polybasic domain would be responsible for vesicle aggregation. It should be noticed that the $\mathrm{N}$-terminal domain of $\operatorname{PrP}^{\mathrm{C}}$ could act as a powerful toxic effector [54]. Deletions in the flexible N-terminal domain produce severe neurodegeneration phenotypes. Protein-protein interactions with the wild type $\mathrm{PrP}^{\mathrm{C}}$ enable the rescue of such phenotypes [55]. Previous studies have shown that the full-length $\operatorname{PrP}$ is responsible for a fusogenic effect of negatively charged vesicles and thus participates in lipid aggregation [24,56]. The nature of the interaction between the positively charged protein and the negatively charged lipid membrane is mainly electrostatic [29]. Evidently, the polybasic region encompassing residues 23-115 is involved in the high amount of binding of full-length PrP to the external surface of the lipid membrane, as has been suggested by many studies [29, 30]. Furthermore, the interaction of the $\mathrm{N}$-terminal domain is specifically established with the phosphatidylserine headgroups [32]. With the BLM technique, we showed that the monomeric moPrP does not induce stepwise ion currents at low bulk concentrations $(<300 \mathrm{nM})$, reinforcing the point of dye release leakage induced by fusion and/or aggregation. Surprisingly, ion currents were reported for monomeric full-length moPrP [57], but this was for hydrophobic membranes containing cholesterol. In our case, we used negatively charged membranes that are a known template for prion fibrillation [29]. If the first adsorbed moPrP monomers were also altered by the lipid surface, the conformational change they underwent involved a lesser content of polypeptide backbone than in the change of the first adsorbed $\mathrm{moH} 2 \mathrm{H} 3$ molecules. We can then propose from the SLS-ThT binding assays that a concentration threshold is needed to produce the lipid-induced full-length moPrPfibrillation, whereas this is not the case for $\mathrm{moH} 2 \mathrm{H} 3$. Considering the co-existence of polydispersed species formed during the lipid-induced fibrillation, it is difficult to decipher which oligomeric species would be membrane-active in the case of the full-length protein [25, 58]. Working at concentrations below $300 \mathrm{nM}$ ensured that the moPrP molecules remained in the monomeric state for the duration of the BLM experiments.

\section{Link between lipid-bound conformational states of oligomers and membrane impairment}

We estimated the conformational differences between soluble oligomers of the full-length sequence and the truncated from restricted to the $\mathrm{H} 2 \mathrm{H} 3$ domain. The two sequences formed oligomers containing 12 monomeric units that exhibited $\beta$-sheeted structure, as previously reported [28] (scheme 1). Here, we report that the soluble oligomers from moPrP and $\mathrm{moH} 2 \mathrm{H} 3$ have different lytic activities towards lipid membranes. When adsorbed or embedded in the lipid membrane, both $\beta$-structured oligomers underwent a conformational change, giving rise to de novo $\beta$-structures with increased ThT affinity. However, the full-length oligomers disrupted the DOPC/DOPS membrane at very low concentrations (above $50 \mathrm{nM}$ ), while the moH2 33 oligomers were mostly inactive in the concentration range of $50-500 \mathrm{nM}$. We previously showed that oligomers from truncated PrP 104-231 and from the full-length sequence are active towards negatively charged lipids through interaction with the transmembrane domain 105-135 [24]. The lower membrane activity of the $\mathrm{moH} 2 \mathrm{H} 3$ oligomers could be explained by the lack of this central region, which contains a palindromic poly-Ala stretch. The accessibility of this hydrophobic domain in the lipid-bound conformers is essential for enabling membrane permeabilization, as suggested by previous studies [59]. $\mathrm{O}_{12} \mathrm{moH} 2 \mathrm{H} 3$ presented a higher ThT binding, corroborating the change in regular $\beta$-sheets to less stacked $\beta$-sheets $\left(1665 \mathrm{~cm}^{-1}\right)$ in the early stage of membrane binding. This observed conformation in the non-saturating condition of the lipid bilayer could be responsible for membrane destabilization, but in a less efficient way. In contrast to oligomers of moH2 $\mathrm{H} 3, \mathrm{O}_{12} \mathrm{moPrP}$ in the lipid-bound showed a decrease in the content of less-stacked $\beta$-sheeted domain $\left(1665 \mathrm{~cm}^{-1}\right)$ and 
an increase in the amount of $\beta$-sheets having a more planar conformation $\left(1622 \mathrm{~cm}^{-1}\right)$ compared to the solution state, leading to a more stable channel-forming structure. This lipid-bound conformation would reorganize the hydrophobic residues on the external surface of the oligomer to minimize its energy when inserted into the lipid bilayer, as further supported by the ANS binding data.

\section{Link between membrane-active oligomers and their neurotoxicity}

An important question regarding the large number of oligomers that form in vitro from amyloidogenic proteins concerns their relevancy for in vivo amyloid processes and their implication in conformationalassociated diseases. The presence of amyloid-associated oligomers was revealed in vivo for $\mathrm{A} \beta[60]$ and $\alpha$-synuclein [61]. Such in vivo-selected oligomers were shown to cause memory impairment following a single brain infusion [60]. Thus far, the neurotoxic effect of soluble exogenous oligomers has generally been tested in primary neuronal cultures, for example, $A \beta$ species [60, 62] and PrP oligomers [12], but the toxicity of small $\mathrm{A} \beta$ oligomers has also been established in vivo [63]. Many studies have attempted to gain structural insights from in vivo-formed oligomers and have shown that they share structural characteristics with those formed in vitro $[64,65]$. Although our understanding of oligomer formation in vivo remains limited, we believe that studies concerning the fate of in vitro-formed oligomers in the neuronal cell environment, and their implications for membrane impairment, can increase our knowledge of the intricate mechanisms of amyloid-cell toxicities. One of the actions of soluble oligomers in amyloid diseases is to disturb cell homeostasis by directly interacting with the cell membrane [20, 66, 67]. A hypothesis was proposed for the toxic activity of prefibrillar oligomers due to the fact that they share a common structure, suggesting that they may also share a common mechanism of toxicity $[64,68,69]$.

In the current study, the exposure of neuronal cells devoid of $\operatorname{PrP}^{\mathrm{C}}$ to submicromolar concentrations of off-pathway oligomers showed that exogenous species from both the full-length and truncated sequences resulted in neuronal death that was linked to their ability to permeabilize lipid membranes (Scheme 2). Indeed, the mechanism of the full-length oligomer is in agreement with channel formation by a well-defined $\beta$-structure, which could be the basis for its neurotoxicity. However, the de novo $\beta$ sheeted lipid-bound conformer from $\mathrm{O}_{12} \mathrm{moH} 2 \mathrm{H} 3$ failed to form defined channels but was shown to destabilize the membrane on the basis of the BLM and dye-release experiments. It is possible that the neurotoxic mechanism of small amyloidogenic oligomers is primarily governed by the degree that their hydrophobic residues are exposed to solvent and is weakly influenced by their secondary structure [69, 70]. In another work, the cytotoxicity of $A \beta$ fibrils was found to be dependent on the primary sequence of A $\beta$ mutant peptides having different hydrophobicities [71]. The ANS experiments we performed to probe the accessibility of the hydrophobic clusters in oligomers of full-length $\mathrm{PrP}$ and $\mathrm{H} 2 \mathrm{H} 3$ revealed a higher exposure of their hydrophobic regions compared to the monomer (Figure S4), thus favoring interaction with lipid membranes. Moreover, the full-length oligomer exhibited a 4-5 fold increase in ANS binding compared to the monomer, while that of $\mathrm{O}_{12} \mathrm{moH} 2 \mathrm{H} 3$ was only 2-fold greater.

Clear evidence that $\operatorname{PrP}^{\mathrm{C}}$ expression is not required for cytoxicity was established for different $\operatorname{Pr} P$ assemblies [72]. Here, our results support the idea that $\operatorname{PrP}^{\mathrm{C}}$ is not required for the neurotoxicity of welldefined off-pathway oligomers. Furthermore, we showed that these oligomeric species exhibited significant toxicity at low dose, at variance with other reports based on use of higher species generated by protein misfolding cyclic amplification or 50-fold higher concentrations [73]. But the most intriguing feature is that neurons expressing homologous $\mathrm{PrP}^{\mathrm{C}}$ exhibited low survival when in contact with the full-length oligomers, whereas survival was recovered when in contact with $\mathrm{O}_{12} \mathrm{moH} 2 \mathrm{H} 3$ compared to the neurons devoid of $\operatorname{PrP}^{\mathrm{C}}$. The cellular form of the prion protein plays a crucial role in prion-mediated neuronal death following interaction with $\operatorname{PrP}^{\mathrm{Sc}}[54,74]$, but its role in toxic signaling is still unclear, as mentioned in studies of other $\beta$-sheet-rich conformers such as amyloid $\beta$ [75-77] or antibody crosslinking [78]. The $\mathrm{N}$-terminus domain of $\mathrm{PrP}^{\mathrm{C}}$ specifically binds to toxic amyloid $\beta$ oligomers and then exerts distinct toxic effects through an unknown mechanism [79]. Recently, electrophysiological studies have clarified the role of the $\mathrm{N}$-terminus domain of the full-length $\operatorname{PrP}^{\mathrm{C}}$ in the appearance of spontaneous ion currents associated with neurotoxic mutants of PrP [54]. Our findings lead us to hypothesize that the 
off-pathway oligomers of the full-length PrP sequence and the $\mathrm{H} 2 \mathrm{H} 3$ helices differ in size, membrane activity, and $\beta$-sheeted structure, with the more hydrophobic external surfaces binding differently to the cellular PrP protein. The full-length oligomers have high affinity towards negatively charged vesicles and would interact less with $\mathrm{PrP}^{\mathrm{C}}$, while the $\mathrm{O}_{12} \mathrm{moH} 2 \mathrm{H} 3$ weakly bind to membranes and would preferentially bind to $\mathrm{PrP}^{\mathrm{C}}$, forming a complex with a neuroprotective effect (Scheme 2). Another possibility is that the full-length oligomers interact with $\mathrm{PrP}^{\mathrm{C}}$ but form complex intermediates with neurotoxicities equal to the initial oligomers. The competitive binding of off-pathway oligomers to $\operatorname{PrP}^{\mathrm{C}}$ or to lipid membranes depends on their conformation, the hydrophobicity of the external surface of their assembly, and the presence of the N-terminal region. Our suggestion is that cellular membrane impairment cannot be excluded in the presence of off-pathway oligomers, producing marked membrane perturbations. The change in the ionic homeostasis across the membrane may be one part of the neurotoxicity exerted by off-pathway species generated in PrP fibrillation. It is also important to define other intermediate species in the fibrillar pathway as potential neurotoxic agents. This could be accomplished by deciphering the role of membrane binding and membrane templating by studying the capability of $\operatorname{PrP}^{\mathrm{C}}$ to bind to complex amyloid conformers.

\section{Author contributions}

Conceived and designed the experiments: CH SC HR SN. Performed the experiments: CH SN SC. Analyzed the data: CH SN SC VB. Contributed reagents/materials/analysis tools: CH SN SC PG HR VB. Wrote the paper: SN.

\section{Conflict of interest}

The authors declare that they have no conflicts of interest with the contents of this article.

\section{Acknowledgments}

The authors would like to thank LabEx MiChem (Sorbonne Universités, part of French state funds under reference ANR-11-IDEX-0004-02) for its financial support in the acquisition of the BLM system 


\section{References}

[1] F. Chiti, C.M. Dobson, Protein misfolding, functional amyloid, and human disease, Annu. Rev. Biochem., 75 (2006) 333-366. http://dx.doi.org/10.1146/annurev.biochem.75.101304.123901.

[2] J. Collinge, Mammalian prions and their wider relevance in neurodegenerative diseases, Nature, 539 (2016) 217-226. https://doi.org/10.1038/nature20415.

[3] C. Scialo, E. De Cecco, P. Manganotti, G. Legname, Prion and Prion-Like Protein Strains: Deciphering the Molecular Basis of Heterogeneity in Neurodegeneration, Viruses, 11 (2019) 261. http://dx.doi.org/10.3390/v11030261.

[4] B. Caughey, G.S. Baron, B. Chesebro, M. Jeffrey, Getting a grip on prions: oligomers, amyloids, and pathological membrane interactions, Annu. Rev. Biochem., 78 (2009) 177-204. http://dx.doi.org/10.1146/annurev.biochem.78.082907.145410.

[5] N.T.T. Le, B. Wu, D.A. Harris, Prion neurotoxicity, Brain Pathol, 29 (2019) 263-277. http://dx.doi.org/10.1111/bpa.12694.

[6] I.V. Baskakov, G. Legname, M.A. Baldwin, S.B. Prusiner, F.E. Cohen, Pathway complexity of prion protein assembly into amyloid, J. Biol. Chem., 277 (2002) 21140-21148. http://dx.doi.org/10.1074/jbc.M111402200.

[7] A. Igel-Egalon, J. Bohl, M. Moudjou, L. Herzog, F. Reine, H. Rezaei, V. Beringue, Heterogeneity and Architecture of Pathological Prion Protein Assemblies: Time to Revisit the Molecular Basis of the Prion Replication Process?, Viruses, 11 (2019) 429. http://dx.doi.org/10.3390/v11050429.

[8] I.H. Solomon, J.A. Schepker, D.A. Harris, Prion Neurotoxicity: Insights from Prion Protein Mutants, Curr. Issues Mol. Biol., 12 (2009) 51-62. http://dx.doi.org/v12/51. [9] M.K. Sandberg, H. Al-Doujaily, B. Sharps, A.R. Clarke, J. Collinge, Prion propagation and toxicity in vivo occur in two distinct mechanistic phases, Nature, 470 (2011) 540-542. http://dx.doi.org/10.1038/nature09768

[10] Y.J. Lee, R. Savtchenko, V.G. Ostapchenko, N. Makarava, I.V. Baskakov, Molecular Structure of Amyloid Fibrils Controls the Relationship between Fibrillar Size and Toxicity, PLoS ONE, 6 (2011) e20244. http://dx.doi.org/10.1371\%2Fjournal.pone.0020244.

[11] W.F. Xue, A.L. Hellewell, E.W. Hewitt, S.E. Radford, Fibril fragmentation in amyloid assembly and cytotoxicity: when size matters, Prion, 4 (2010) 20-25. https://doi.org/10.4161/pri.4.1.11378.

[12] S. Simoneau, H. Rezaei, N. Sales, G. Kaiser-Schulz, M. Lefebvre-Roque, C. Vidal, J.G. Fournier, J. Comte, F. Wopfner, J. Grosclaude, H. Schatzl, C.I. Lasmezas, In vitro and in vivo neurotoxicity of prion protein oligomers, PLoS Pathog., 3 (2007) 1175-1186.

http://dx.doi.org/10.1371/journal.ppat.0030125.

[13] P. Cizas, R. Budvytyte, R. Morkuniene, R. Moldovan, M. Broccio, M. Lösche, G. Niaura, G. Valincius, V. Borutaite, Size-dependent neurotoxicity of b-amyloid oligomers, Arch. Biochem. Biophys., 496 (2010) 84-92. https://doi.org/10.1016/j.abb.2010.02.001. [14] J. Kazlauskaite, A. Young, C.E. Gardner, J.V. Macpherson, C. Venien-Bryan, T.J. Pinheiro, An unusual soluble beta-turn-rich conformation of prion is involved in fibril formation and toxic to neuronal cells, Biochem. Biophys. Res. Commun., 328 (2005) 292305. http://dx.doi.org/10.1016/j.bbrc.2004.12.172.

[15] M. Zhu, S. Han, F. Zhou, S.A. Carter, A.L. Fink, Annular Oligomeric Amyloid Intermediates Observed by in Situ Atomic Force Microscopy, J. Biol. Chem., 279 (2004) 24452-24459. http://dx.doi.org/10.1074/jbc.M400004200 
[16] O.V. Bocharova, L. Breydo, A.S. Parfenov, V.V. Salnikov, I.V. Baskakov, In vitro Conversion of Full-length Mammalian Prion Protein Produces Amyloid Form with Physical Properties of PrPSc, J. Mol. Biol., 346 (2005) 645-659.

https://doi.org/10.1016/j.jmb.2004.11.068.

[17] F. Bemporad, F. Chiti, Protein misfolded oligomers: experimental approaches, mechanism of formation, and structure-toxicity relationships, Chem. Biol., 19 (2012) 315327. http://dx.doi.org/10.1016/j.chembiol.2012.02.003.

[18] H. Jang, F.T. Arce, S. Ramachandran, R. Capone, R. Lal, R. Nussinov, [beta]-Barrel Topology of Alzheimer's [beta]-Amyloid Ion Channels, J. Mol. Biol., 404 (2010) 917-934. https://doi.org/10.1016/j.jmb.2010.10.025.

[19] R. Kayed, Y. Sokolov, B. Edmonds, T.M. McIntire, S.C. Milton, J.E. Hall, C.G. Glabe, Permeabilization of lipid bilayers is a common conformation-dependent activity of soluble amyloid oligomers in protein misfolding diseases, J. Biol. Chem., 279 (2004) 46363-46366. http://dx.doi.org/10.1074/jbc.C400260200.

[20] H.A. Lashuel, D. Hartley, B.M. Petre, T. Walz, P.T. Lansbury, Jr., Neurodegenerative disease: amyloid pores from pathogenic mutations, Nature, 418 (2002) 291.

http://dx.doi.org/10.1038/418291a.

[21] H. Jang, J. Zheng, R. Nussinov, Models of [beta]-Amyloid Ion Channels in the Membrane Suggest That Channel Formation in the Bilayer Is a Dynamic Process, Biophys. J., 93 (2007) 1938-1949. http://dx.doi.org/10.1529/biophysj.107.110148.

[22] E. Biasini, U. Unterberger, I.H. Solomon, T. Massignan, A. Senatore, H. Bian, T.

Voigtlaender, F.P. Bowman, V. Bonetto, R. Chiesa, J. Luebke, P. Toselli, D.A. Harris, A mutant prion protein sensitizes neurons to glutamate-induced excitotoxicity, J Neurosci, 33 (2013) 2408-2418. http://dx.doi.org/10.1523/JNEUROSCI.3406-12.2013.

[23] H.A. Lashuel, P.T. Lansbury, Jr., Are amyloid diseases caused by protein aggregates that mimic bacterial pore-forming toxins?, Q. Rev. Biophys., 39 (2006) 167-201.

http://dx.doi.org/10.1017/S0033583506004422.

[24] J.F. Chich, C. Chapuis, C. Henry, J. Vidic, H. Rezaei, S. Noinville, Vesicle permeabilization by purified soluble oligomers of prion protein: a comparative study of the interaction of oligomers and monomers with lipid membranes, J. Mol. Biol., 397 (2010) 10171030. http://dx.doi.org/10.1016/j.jmb.2010.02.013.

[25] S. Combet, F. Cousin, H. Rezaei, S. Noinville, Membrane interaction of off-pathway prion oligomers and lipid-induced on-pathway intermediates during prion conversion: A clue for neurotoxicity, Biochim. Biophys. Acta Biomembr., 1861 (2019) 514-523.

https://doi.org/10.1016/j.bbamem.2018.12.001.

[26] F. Eghiaian, T. Daubenfeld, Y. Quenet, M. van Audenhaege, A.P. Bouin, G. van der Rest, J. Grosclaude, H. Rezaei, Diversity in prion protein oligomerization pathways results from domain expansion as revealed by hydrogen/deuterium exchange and disulfide linkage, Proc. Natl. Acad. Sci. U.S.A., 104 (2007) 7414-7419.

http://dx.doi.org/10.1073/pnas.0607745104.

[27] M. Adrover, K. Pauwels, S. Prigent, C. de Chiara, Z. Xu, C.1. Chapuis, A. Pastore, H. Rezaei, Prion Fibrillization Is Mediated by a Native Structural Element That Comprises Helices H2 and H3, J. Biol. Chem., 285 (2010) 21004-21012.

http://dx.doi.org/10.1074/jbc.M110.111815.

[28] N. Chakroun, S. Prigent, C.A. Dreiss, S. Noinville, C. Chapuis, F. Fraternali, H. Rezaei, The oligomerization properties of prion protein are restricted to the $\mathrm{H} 2 \mathrm{H} 3$ domain, FASEB J., 24 (2010) 3222-3231. http://dx.doi.org/10.1096/fj.09-153924.

[29] N. Sanghera, Bruno E.F.S. Correia, Joana R.S. Correia, C. Ludwig, S. Agarwal, Hironori K. Nakamura, K. Kuwata, E. Samain, Andrew C. Gill, Boyan B. Bonev, Teresa J.T. Pinheiro, Deciphering the Molecular Details for the Binding of the Prion Protein to Main 
Ganglioside GM1 of Neuronal Membranes, Chem. Biol., 18 (2011) 1422-1431. https://doi.org/10.1016/j.chembiol.2011.08.016.

[30] M. Morillas, W. Swietnicki, P. Gambetti, W.K. Surewicz, Membrane environment alters the conformational structure of the recombinant human prion protein, J. Biol. Chem., 274 (1999) 36859-36865. http://dx.doi.org/10.1074/jbc.274.52.36859

[31] H.I. Ingolfsson, M.N. Melo, F.J. van Eerden, C.m. Arnarez, C.A. Lopez, T.A.

Wassenaar, X. Periole, A.H. de Vries, D.P. Tieleman, S.J. Marrink, Lipid Organization of the Plasma Membrane, J. Am. Chem. Soc., 136 (2014) 14554-14559.

https://doi.org/10.1021/ja507832e

[32] C.L. Haigh, C. Tumpach, S.C. Drew, S.J. Collins, The Prion Protein N1 and N2

Cleavage Fragments Bind to Phosphatidylserine and Phosphatidic Acid; Relevance to Stress-

Protection Responses, Plos ONE, 10 (2015). http://dx.doi.org/10.1371/journal.pone.0134680.

[33] H. Rezaei, D. Marc, Y. Choiset, M. Takahashi, G. Hui Bon Hoa, T. Haertle, J.

Grosclaude, P. Debey, High yield purification and physico-chemical properties of full-length recombinant allelic variants of sheep prion protein linked to scrapie susceptibility, Eur. J. Biochem., 267 (2000) 2833-2839. http://dx.doi.org/10.1046/j.1432-1033.2000.01347.x. [34] I. Faye, C. Huin, N. Illy, V. Bennevault, P. Guegan, beta-Cyclodextrin-Based Star Amphiphilic Copolymers: Synthesis, Characterization, and Evaluation as Artificial Channels, Macromol. Chem. Phys., 220 (2018) 1800308. https://doi.org/10.1002/macp.201800308. [35] R. Richter, A. Mukhopadhyay, A. Brisson, Pathways of Lipid Vesicle Deposition on Solid Surfaces: A Combined QCM-D and AFM Study, Biophys. J., 85 (2003) 3035-3047. https://doi.org/10.1016/S0006-3495(03)74722-5.

[36] M. Revault, H. Quiquampoix, M.H. Baron, S. Noinville, Fate of prions in soil: trapped conformation of full-length ovine prion protein induced by adsorption on clays, Biochim. Biophys. Acta, 1724 (2005) 367-374. http://dx.doi.org/10.1016/j.bbagen.2005.05.005. [37] B. Shivu, S. Seshadri, J. Li, K.A. Oberg, V.N. Uversky, A.L. Fink, Distinct beta-Sheet Structure in Protein Aggregates Determined by ATR-FTIR Spectroscopy, Biochemistry, 52 (2013) 5176-5183. http://dx.doi.org/10.1021/bi400625v.

[38] H. Susi, D.M. Byler, Fourier transform infrared study of proteins with parallel betachains, Arch. Biochem. Biophys., 258 (1987) 465-469. http://dx.doi.org/10.1016/00039861(87)90367-5.

[39] H. Bueler, M. Fischer, Y. Lang, H. Bluethmann, H.P. Lipp, S.J. DeArmond, S.B. Prusiner, M. Aguet, C. Weissmann, Normal development and behaviour of mice lacking the neuronal cell-surface PrP protein, Nature, 356 (1992) 577-582.

http://dx.doi.org/10.1038/356577a0.

[40] M. Fischer, T. Rulicke, A. Raeber, A. Sailer, M. Moser, B. Oesch, S. Brandner, A. Aguzzi, C. Weissmann, Prion protein (PrP) with amino-proximal deletions restoring susceptibility of PrP knockout mice to scrapie, Embo J., 15 (1996) 1255-1264.

https://doi.org/10.1002/j.1460-2075.1996.tb00467.x

[41] S. Cronier, H. Laude, J.M. Peyrin, Prions can infect primary cultured neurons and astrocytes and promote neuronal cell death, Proc. Natl. Acad. Sci. U. S. A., 101 (2004) 12271-12276. http://dx.doi.org/10.1073/pnas.0402725101.

[42] S. Cronier, V. Beringue, A. Bellon, J.M. Peyrin, H. Laude, Prion strain- and speciesdependent effects of antiprion molecules in primary neuronal cultures, J. Virol., 81 (2007) 13794-13800. http://dx.doi.org/10.1128/JVI.01502-07.

[43] A. Dong, J. Matsuura, M.C. Manning, J.F. Carpenter, Intermolecular beta-sheet results from trifluoroethanol-induced nonnative alpha-helical structure in beta-sheet predominant proteins: infrared and circular dichroism spectroscopic study, Arch. Biochem. Biophys., 355 (1998) 275-281. https://doi.org/10.1006/abbi.1998.0718. 
[44] G. Zandomeneghi, M.R. Krebs, M.G. McCammon, M. Fandrich, FTIR reveals structural differences between native beta-sheet proteins and amyloid fibrils, Protein Sci., 13 (2004) 3314-3321. https://doi.org/10.1110/ps.041024904.

[45] R. Sarroukh, E. Goormaghtigh, J.-M. Ruysschaert, V. Raussens, ATR-FTIR: A rejuvenated tool to investigate amyloid proteins, Biochim. Biophys. Acta Biomembr., 1828 (2013) 2328-2338. https://doi.org/10.1016/j.bbamem.2013.04.012.

[46] Z. Xu, M. Adrover, A. Pastore, S. Prigent, F. Mouthon, E. Comoy, H. Rezaei, J.-P. Deslys, Mechanistic insights into cellular alteration of prion by poly-d-lysine: the role of H2H3 domain, FASEB J., 25 (2011) 3426-3435. http://dx.doi.org/10.1096/fj.11-187534. [47] S. Hayward, E. James Milner-White, Simulation of the $\beta$ - to $\alpha$-sheet transition results in a twisted sheet for antiparallel and an $\alpha$-nanotube for parallel strands: Implications for amyloid formation, Proteins Struct. Funct. Bioinform., 79 (2011) 3193-3207. http://dx.doi.org/10.1002/prot.23154.

[48] S.J. Roeters, A. Iyer, G. Pletikapic, V. Kogan, V. Subramaniam, S. Woutersen, Evidence for Intramolecular Antiparallel Beta-Sheet Structure in Alpha-Synuclein Fibrils from a Combination of Two-Dimensional Infrared Spectroscopy and Atomic Force Microscopy, Sci. Rep., 7 (2017) 41051. http://dx.doi.org/10.1038/srep41051.

[49] A. Sakudo, K. Ikuta, Prion protein functions and dysfunction in prion diseases, Curr. Med. Chem., 16 (2009) 380-389. http://dx.doi.org/10.2174/092986709787002673.

[50] S. Noinville, M. Revault, Conformations of Proteins Adsorbed at Liquid-Solid Interfaces, in: P. Déjardin (Ed.) Proteins at Solid-Liquid Interfaces, Springer Berlin Heidelberg, Berlin, Heidelberg, 2006, pp. 119-150. http://dx.doi.org/10.1007/3-540-32658-8_6.

[51] N. Chakroun, A. Fornili, S. Prigent, J. Kleinjung, C.A. Dreiss, H. Rezaei, F. Fraternali, Decrypting Prion Protein Conversion into a beta-Rich Conformer by Molecular Dynamics, J. Chem. Theory Comput., 9 (2013) 2455-2465. http://dx.doi.org/10.1021/ct301118j.

[52] J. Singh, H. Kumar, A.T. Sabareesan, J.B. Udgaonkar, Rational stabilization of helix 2 of the prion protein prevents its misfolding and oligomerization, J. Am. Chem. Soc., 136 (2014) 16704-16707. http://dx.doi.org/10.1021/ja510964t.

[53] M. Groenning, Binding mode of Thioflavin T and other molecular probes in the context of amyloid fibrils-current status, J. Chem. Biol., 3 (2009) 1-18.

http://dx.doi.org/10.1007/s12154-009-0027-5.

[54] B. Wu, A.J. McDonald, K. Markham, C.B. Rich, K.P. McHugh, J. Tatzelt, D.W. Colby, G.L. Millhauser, D.A. Harris, The N-terminus of the prion protein is a toxic effector regulated by the C-terminus, Elife, 6 (2017). http://dx.doi.org/10.7554/eLife.23473.

[55] A. Li, P. Piccardo, S.J. Barmada, B. Ghetti, D.A. Harris, Prion protein with an octapeptide insertion has impaired neuroprotective activity in transgenic mice, EMBO J, 26 (2007) 2777-2785. http://dx.doi.org/10.1038/sj.emboj.7601726.

[56] T. Pillot, L. Lins, M. Goethals, B. Vanloo, J. Baert, J. Vandekerckhove, M. Rosseneu, R. Brasseur, The 118-135 peptide of the human prion protein forms amyloid fibrils and induces liposome fusion, J. Mol. Biol., 274 (1997) 381-393.

http://dx.doi.org/10.1006/jmbi.1997.1382.

[57] AmbadiÂA T. Sabareesan, J. Singh, S. Roy, JayantÂ B. Udgaonkar, M.K. Mathew, The Pathogenic A116V Mutation Enhances Ion-Selective Channel Formation by Prion Protein in Membranes, Biophys. J., 110 (2016) 1766-1776. https://doi.org/10.1016/j.bpj.2016.03.017. [58] S.M. Butterfield, H.A. Lashuel, Amyloidogenic Protein-Membrane Interactions: Mechanistic Insight from Model Systems, Ang. Chem. Int. Ed., 49 (2010) 5628-5654. https://doi.org/10.1002/anie.200906670.

[59] S. Sauve, D. Buijs, G. Gingras, Y. Aubin, Interactions between the conserved hydrophobic region of the prion protein and dodecylphosphocholine micelles, J. Biol. Chem., 287 (2012) 1915-1922. http://dx.doi.org/10.1074/jbc.M111.279364. 
[60] G.M. Shankar, S. Li, T.H. Mehta, A. Garcia-Munoz, N.E. Shepardson, I. Smith, F.M. Brett, M.A. Farrell, M.J. Rowan, C.A. Lemere, C.M. Regan, D.M. Walsh, B.L. Sabatini, D.J. Selkoe, Amyloid-beta protein dimers isolated directly from Alzheimer's brains impair synaptic plasticity and memory, Nat. Med., 14 (2008) 837-842. http://dx.doi.org/10.1038/nm1782.

[61] I.F. Tsigelny, L. Crews, P. Desplats, G.M. Shaked, Y. Sharikov, H. Mizuno, B. Spencer, E. Rockenstein, M. Trejo, O. Platoshyn, J.X. Yuan, E. Masliah, Mechanisms of hybrid oligomer formation in the pathogenesis of combined Alzheimer's and Parkinson's diseases, PLoS ONE, 3 (2008) e3135. http://dx.doi.org/10.1371/journal.pone.0003135.

[62] C. Ji, C. Song, P. Zuo, The mechanism of memory impairment induced by Abeta chronic administration involves imbalance between cytokines and neurotrophins in the rat hippocampus, Curr. Alzheimer Res., 8 (2011) 410-420. http://dx.doi.org/10.2174/156720511795745366.

[63] J. Brouillette, R. Caillierez, N. Zommer, C. Alves-Pires, I. Benilova, D. Blum, B. De Strooper, L. Buee, Neurotoxicity and memory deficits induced by soluble low-molecularweight amyloid-beta1-42 oligomers are revealed in vivo by using a novel animal model, J. Neurosci. , 32 (2012) 7852-7861. http://dx.doi.org/10.1523/JNEUROSCI.5901-11.2012. [64] R. Kayed, E. Head, J.L. Thompson, T.M. McIntire, S.C. Milton, C.W. Cotman, C.G. Glabe, Common Structure of Soluble Amyloid Oligomers Implies Common Mechanism of Pathogenesis, Science, 300 (2003) 486-489. http://dx.doi.org/10.1126/science.1079469 [65] C.A. Lasagna-Reeves, D.L. Castillo-Carranza, U. Sengupta, J. Sarmiento, J. Troncoso, G.R. Jackson, R. Kayed, Identification of oligomers at early stages of tau aggregation in Alzheimer's disease, FASEB J., 26 (2012) 1946-1959. http://dx.doi.org/10.1096/fj.11-199851. [66] P.I. Moreira, M.S. Santos, A. Moreno, A.C. Rego, C. Oliveira, Effect of amyloid betapeptide on permeability transition pore: A comparative study, J. Neurosci. Res., 69 (2002) 257-267. http://dx.doi.org/10.1002/jnr.10282.

[67] D.C. Bode, M.D. Baker, J.H. Viles, Ion Channel Formation by Amyloid-beta42 Oligomers but Not Amyloid-beta40 in Cellular Membranes, J. Biol. Chem., 292 (2017) 14041413. http://dx.doi.org/10.1074/jbc.M116.762526.

[68] C.G. Glabe, Structural Classification of Toxic Amyloid Oligomers, J. Biol. Chem., 283 (2008) 29639-29643. http://dx.doi.org/10.1074/jbc.R800016200.

[69] S. Campioni, B. Mannini, M. Zampagni, A. Pensalfini, C. Parrini, E. Evangelisti, A. Relini, M. Stefani, C.M. Dobson, C. Cecchi, F. Chiti, A causative link between the structure of aberrant protein oligomers and their toxicity, Nat. Chem. Biol., 6 (2010) 140-147. http://dx.doi.org/10.1038/nchembio.283.

[70] B. Bolognesi, J.R. Kumita, T.P. Barros, E.K. Esbjorner, L.M. Luheshi, D.C. Crowther, M.R. Wilson, C.M. Dobson, G. Favrin, J.J. Yerbury, ANS Binding Reveals Common Features of Cytotoxic Amyloid Species, ACS Chem. Biol., 5 (2010) 735-740. http://dx.doi.org/10.1021/cb1001203

[71] Y. Yoshiike, T. Akagi, A. Takashima, Surface structure of amyloid-beta fibrils contributes to cytotoxicity, Biochemistry, 46 (2007) 9805-9812.

http://dx.doi.org/10.1021/bi700455c.

[72] L. Fioriti, E. Quaglio, T. Massignan, L. Colombo, R.S. Stewart, M. Salmona, D.A. Harris, G. Forloni, R. Chiesa, The neurotoxicity of prion protein (PrP) peptide 106-126 is independent of the expression level of PrP and is not mediated by abnormal PrP species, Mol. Cell Neurosci., 28 (2005) 165-176. http://dx.doi.org/10.1016/j.mcn.2004.09.006.

[73] Z. Yuan, L.F. Yang, B.A. Chen, T. Zhu, M.F. Hassan, X.M. Yin, X.M. Zhou, D.M. Zhao, Protein misfolding cyclic amplification induces the conversion of recombinant prion protein to PrP oligomers causing neuronal apoptosis, J. Neurochem., 133 (2015) 722-729. http://dx.doi.org/10.1111/jnc.13098. 
[74] G. Mallucci, A. Dickinson, J. Linehan, P.C. Klohn, S. Brandner, J. Collinge, Depleting neuronal PrP in prion infection prevents disease and reverses spongiosis, Science, 302 (2003) 871-874. http://dx.doi.org/10.1126/science.1090187.

[75] J. Lauren, D.A. Gimbel, H.B. Nygaard, J.W. Gilbert, S.M. Strittmatter, Cellular prion protein mediates impairment of synaptic plasticity by amyloid-beta oligomers, Nature, 457 (2009) 1128-1132. http://dx.doi.org/10.1038/nature07761.

[76] U.K. Resenberger, A. Harmeier, A.C. Woerner, J.L. Goodman, V. Muller, R. Krishnan, R.M. Vabulas, H.A. Kretzschmar, S. Lindquist, F.U. Hartl, G. Multhaup, K.F. Winklhofer, J. Tatzelt, The cellular prion protein mediates neurotoxic signalling of beta-sheet-rich conformers independent of prion replication, Embo J., 30 (2011) 2057-2070.

http://dx.doi.org/10.1038/emboj.2011.86.

[77] H.B. Nygaard, S.M. Strittmatter, Cellular prion protein mediates the toxicity of betaamyloid oligomers: implications for Alzheimer disease, Arch. Neurol., 66 (2009) 1325-1328. http://dx.doi.org/10.1001/archneurol.2009.223.

[78] L. Solforosi, J.R. Criado, D.B. McGavern, S. Wirz, M. Sanchez-Alavez, S. Sugama, L.A. DeGiorgio, B.T. Volpe, E. Wiseman, G. Abalos, E. Masliah, D. Gilden, M.B. Oldstone, B. Conti, R.A. Williamson, Cross-linking cellular prion protein triggers neuronal apoptosis in vivo, Science, 303 (2004) 1514-1516. http://dx.doi.org/10.1126/science.1094273.

[79] B.R. Fluharty, E. Biasini, M. Stravalaci, A. Sclip, L. Diomede, C. Balducci, P. La Vitola, M. Messa, L. Colombo, G. Forloni, T. Borsello, M. Gobbi, D.A. Harris, An N-terminal fragment of the prion protein binds to amyloid-beta oligomers and inhibits their neurotoxicity in vivo, J. Biol. Chem., 288 (2013) 7857-7866. http://dx.doi.org/10.1074/jbc.M112.423954. 
FIGURES AND FIGURES LEGENDS

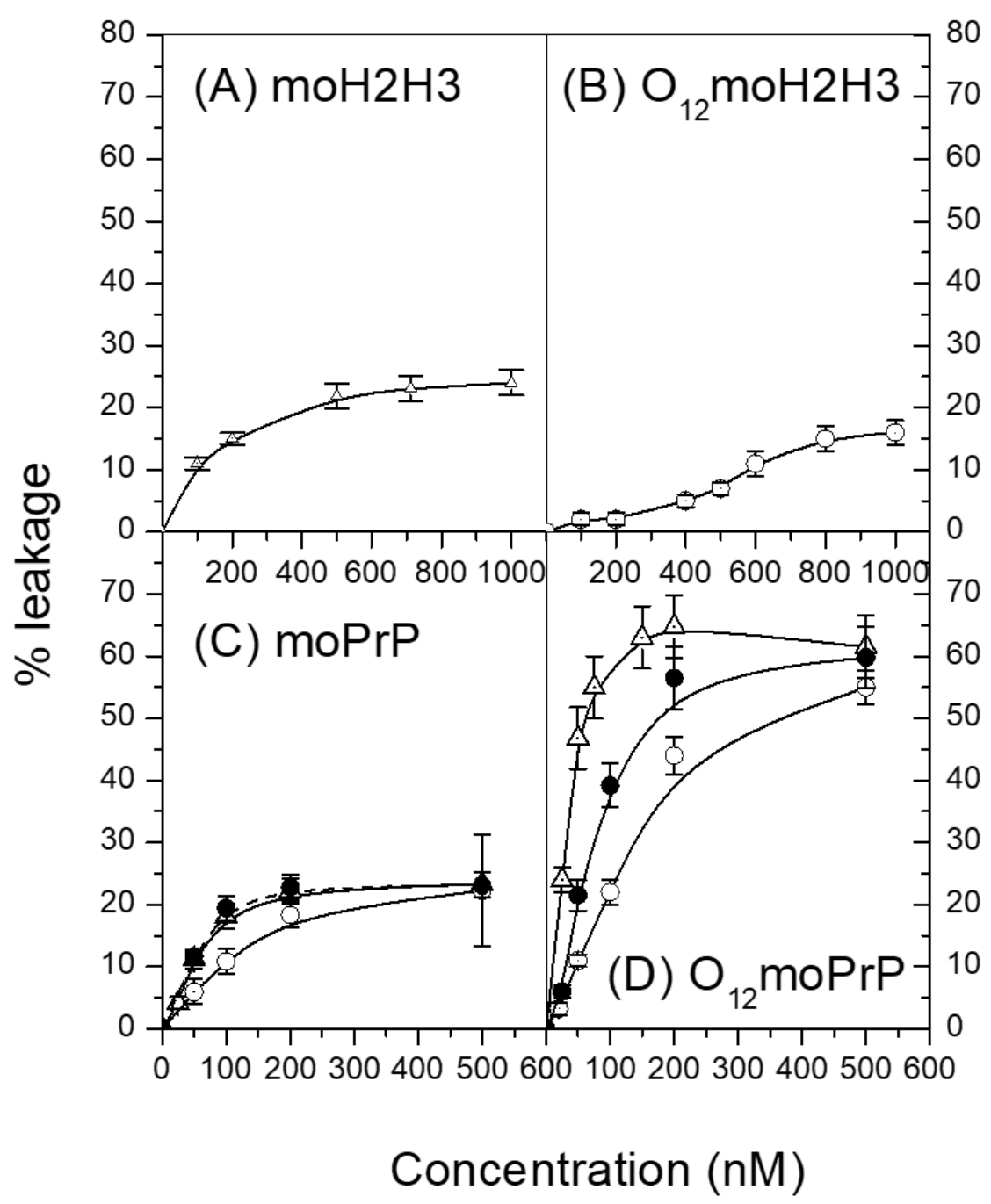

Figure 1: Effect of protein concentration on dye release from DOPC/DOPS vesicles at $\mathrm{pH}$ 6.8: at lipid concentration of $125 \mu \mathrm{M}$ for monomeric moH2H3 (A) and for oligomers of moH2H3 (B), and with different constant lipid concentration $(\triangle) 62.5 \mu \mathrm{M}$, (•) $125 \mu \mathrm{M}$; (O) $250 \mu \mathrm{M}$ for monomeric moPrP (C) and for oligomers of moPrP (D). The results are expressed as mean value \pm SD for at least two independent experiments (Curves are presented for eye guidance only). 


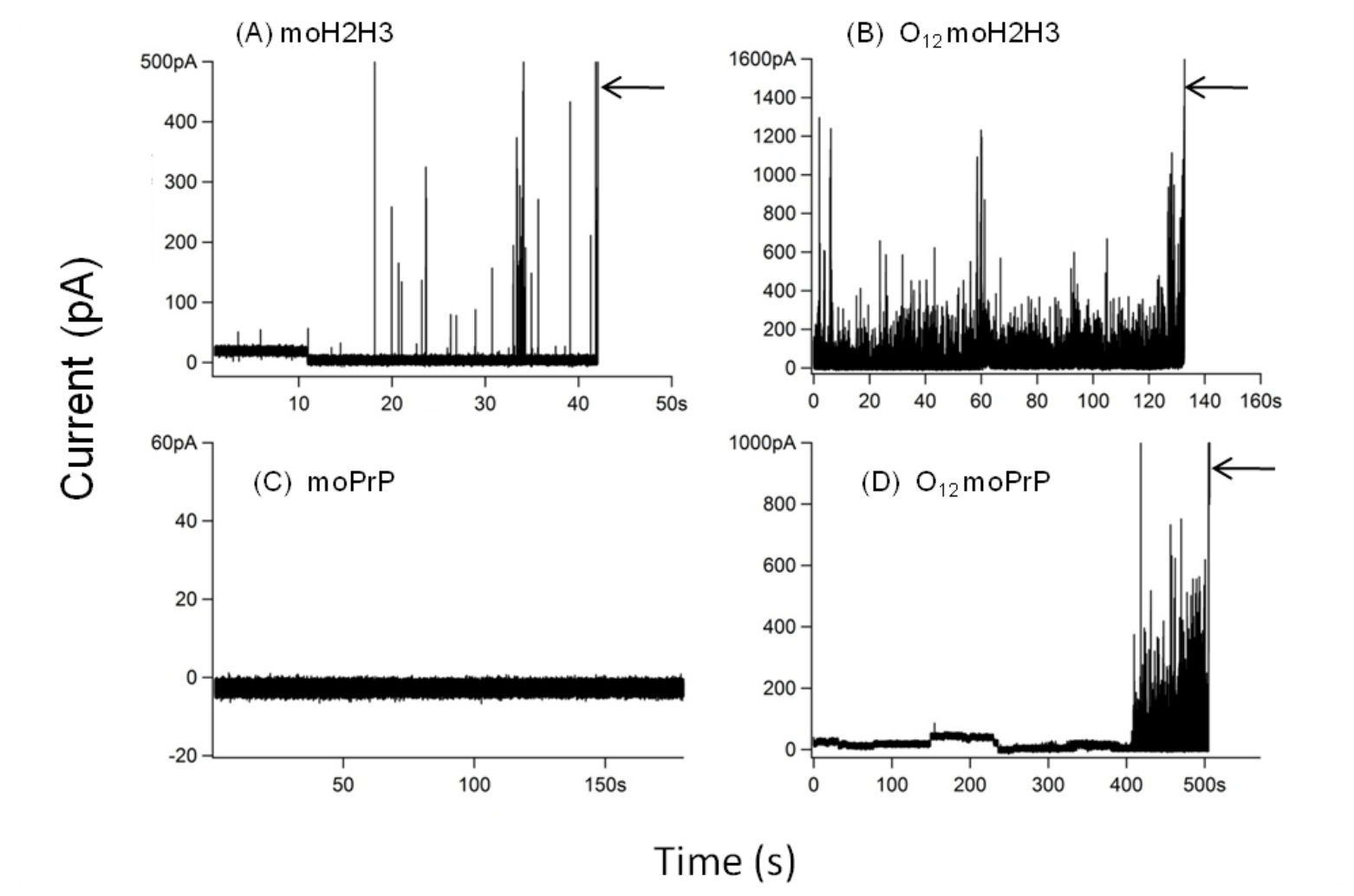

Figure 2: Electrical measurements with DOPC/DOPS planar bilayers at $\mathrm{pH}$ 6.8, for an applied voltage of $+100 \mathrm{mV}$, for monomeric $\mathrm{moH} 2 \mathrm{H} 3$, at $280 \mathrm{nM}$ (A) and for $\mathrm{O}_{12} \mathrm{moH} 2 \mathrm{H} 3$ at $60 \mathrm{nM}$ (B) for an applied voltage of $+50 \mathrm{mV}$, for monomeric moPrP at $272 \mathrm{nM}(\mathrm{C})$ and for $\mathrm{O}_{12} \mathrm{moPrP}$ at $30 \mathrm{nM}$ (D). Black Arrow representing the disruption of the bilayer. 


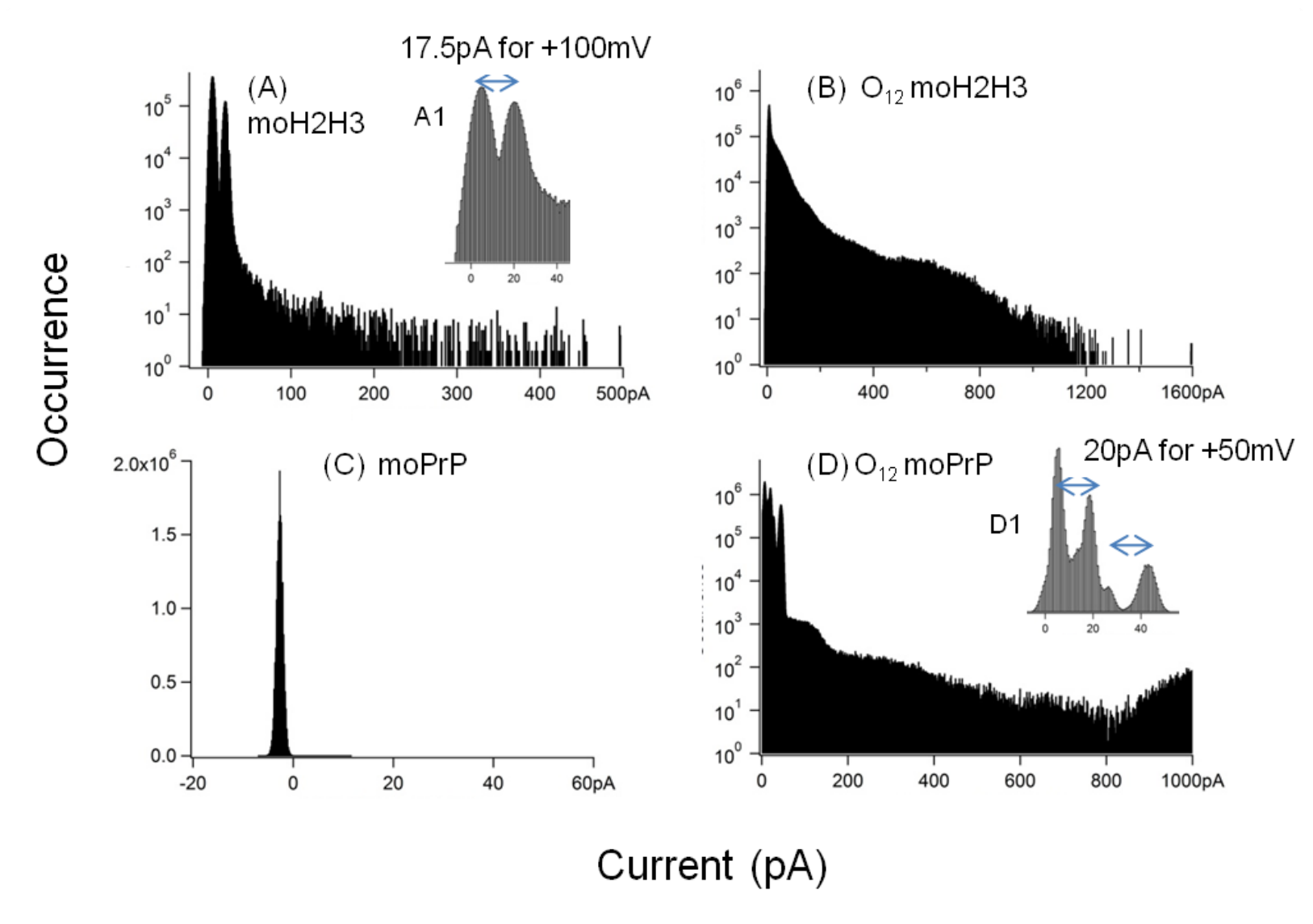

Figure 3: Data analysis of the electrical measurements with DOPC/DOPS planar bilayers at $\mathrm{pH} 6.8$, for an applied voltage of $+100 \mathrm{mV}$, for monomeric $\mathrm{moH} 2 \mathrm{H} 3$, at $280 \mathrm{nM}$ (A) (zoom A1) and for $\mathrm{O}_{12}$ $\mathrm{moH} 2 \mathrm{H} 3$ at $60 \mathrm{nM}(\mathrm{B})$ for an applied voltage of $+50 \mathrm{mV}$, for monomeric moPrP at $272 \mathrm{nM}$ (C) and for $\mathrm{O}_{12} \mathrm{moPrP}$ at $30 \mathrm{nM}(\mathrm{D})$. 


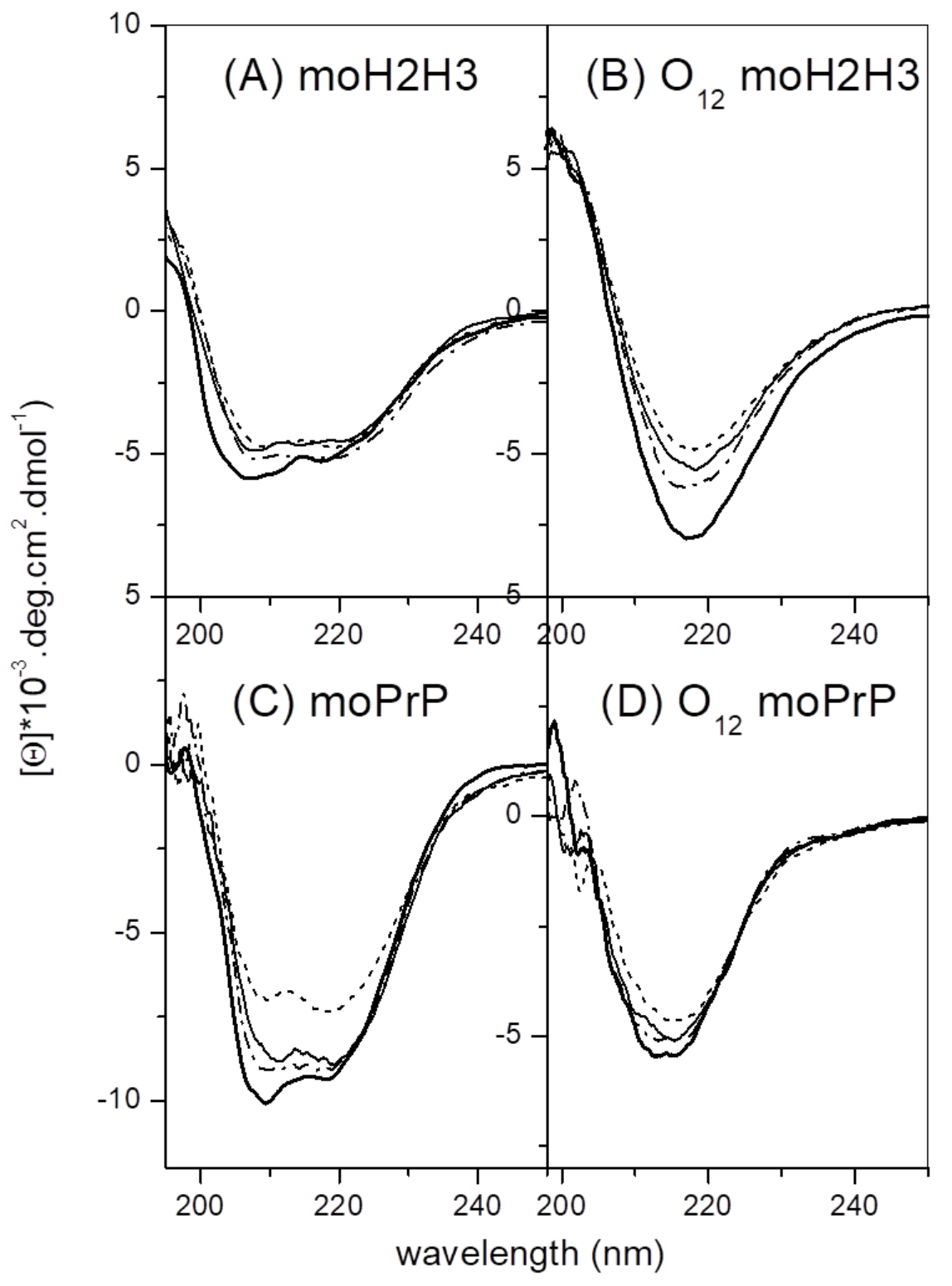

Figure 4: $\mathrm{CD}$ spectra of (A) monomeric $\mathrm{H} 2 \mathrm{H} 3$ at $20 \mu \mathrm{M}$ (bold line) and in presence of lipid vesicles at $\mathrm{L} / \mathrm{P}$ of 15.5/1 (dot dashed line), 12/1 (plan line) and 6.25/1 (short dashed line), and (B) $\mathrm{O}_{12} \mathrm{moH} 2 \mathrm{H} 3$ at $30 \mu \mathrm{M}$ (bold line) and in presence of lipid vesicles at $\mathrm{L} / \mathrm{P}$ of 0.4/1 (dot dashed line), $0.2 / 1$ (plan line) and $0.1 / 1$ (short dashed line), (C) monomeric moPrP at $10 \mu \mathrm{M}$ (bold line) and in presence of lipid vesicles at L/P of 31/1 (dot dashed line), 24/1 (plan line) and 12/1 (short dashed line), and (D) $\mathrm{O}_{12} \mathrm{moPrP}$ at 22 $\mu \mathrm{M}$ (bold line) and in presence of lipid vesicles at L/P of 2.8/1 (dot dashed line), 1.2/1 (plan line) and $0.6 / 1$ (short dashed line). 

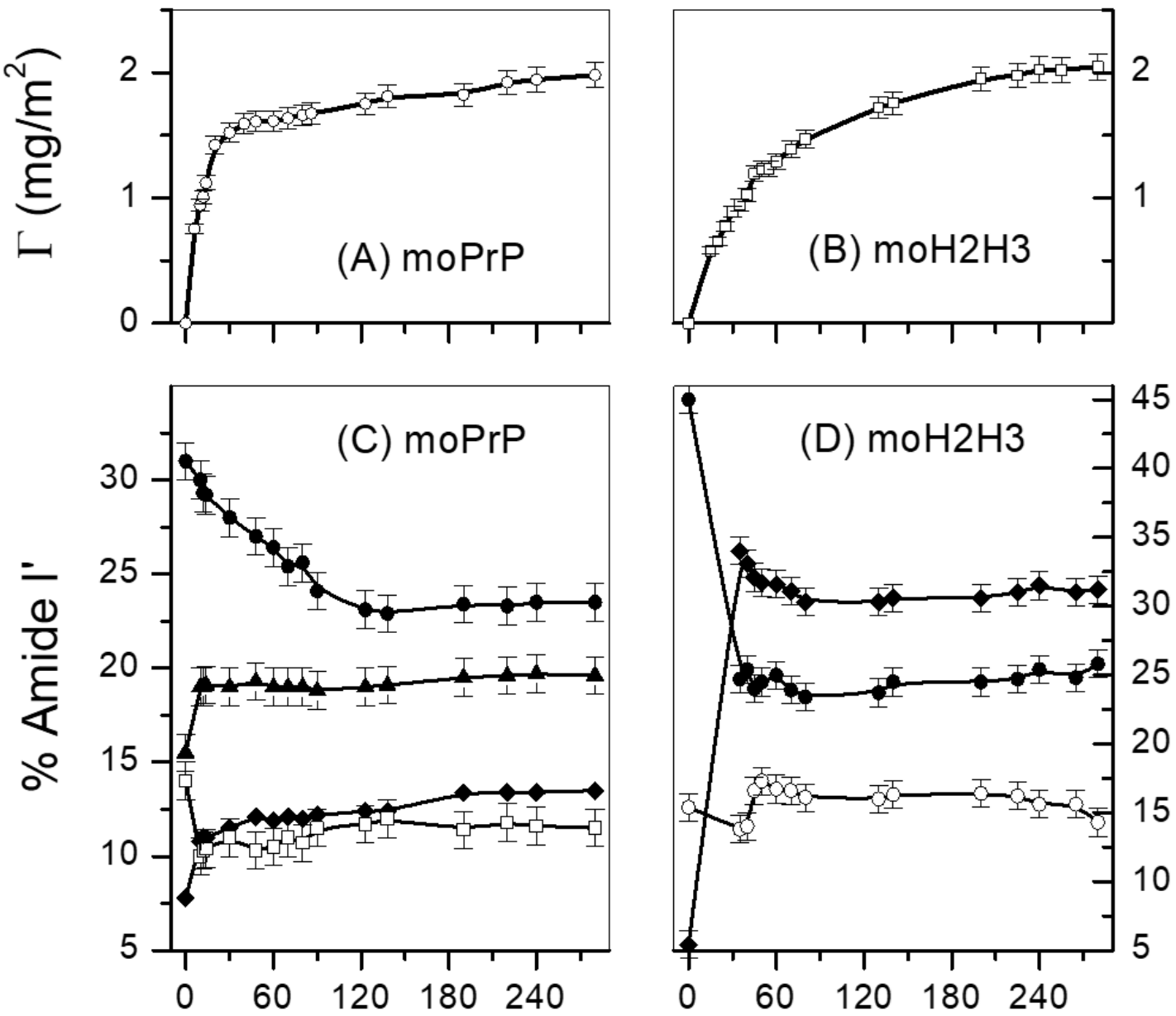

Time $(\min )$

Figure 5: Adsorbed protein amount $(\Gamma)$ onto supported DOPC/DOPS bilayer for the monomeric moPrP at a bulk concentration of $5 \mu \mathrm{M}(\mathrm{A})$ and monomeric moH2H3 at $15 \mu \mathrm{M}(\mathrm{B})$. The results are presented as the mean $\pm \mathrm{SD}$ of two independent experiments. The change in protein secondary structure monitored with time for monomeric moPrP (C) with the \% of the infrared component band area at $1614 \mathrm{~cm}^{-1}$ (diamond), at $1623 \mathrm{~cm}^{-1}$ (triangle), at $1650 \mathrm{~cm}^{-1}$ (circle) and at $1665 \mathrm{~cm}^{-1}$ (open square); for monomeric moH2H3 (D) with the component bands at $1614 \mathrm{~cm}^{-1}$ (diamond), at $1640 \mathrm{~cm}^{-1}$ (open circle) and at 1650 $\mathrm{cm}^{-1}$ (full circle). The \% Amide I' is for one representative experiment. The error bars are standard errors and are shown except for sake of clarity. 

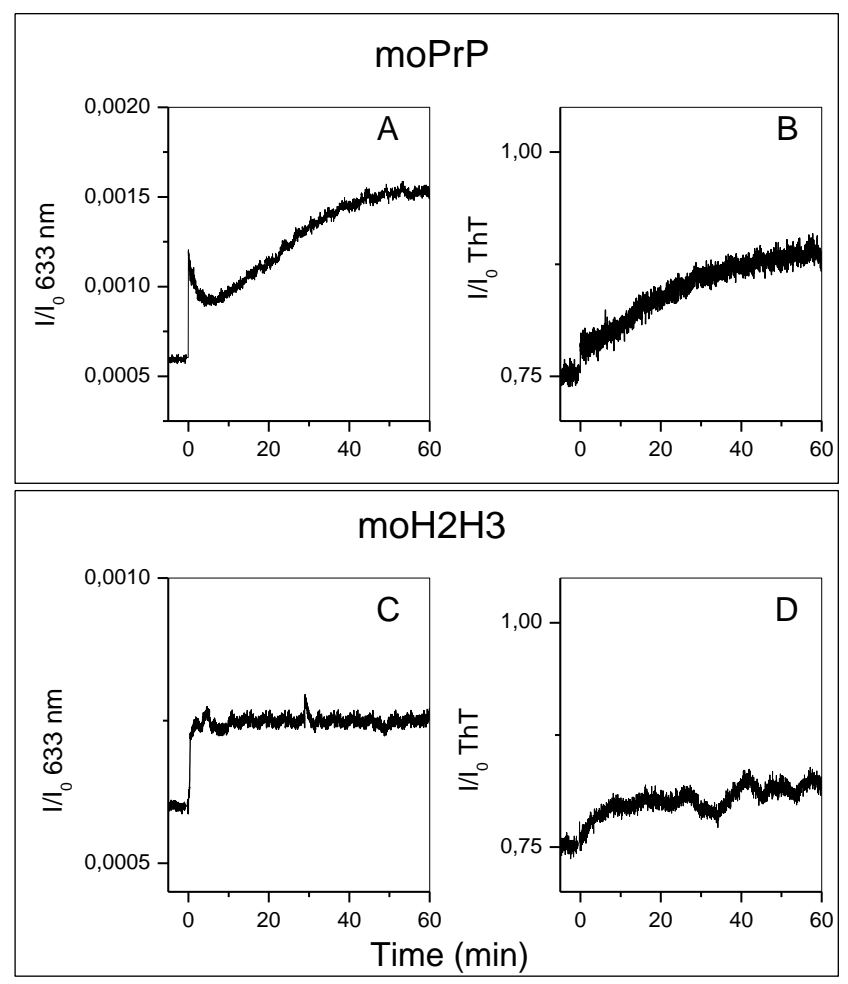

Figure 6: SLS (left) and ThT binding (right) experiments for moPrP monomers at a concentration of 2 $\mu \mathrm{M}$ brought into contact with liposomes DOPC/DOPS at $250 \mu \mathrm{M}$ at time $0(\mathrm{~A}, \mathrm{~B})$ for the moH2H3 monomer at a concentration of $5 \mu \mathrm{M}$ in the same conditions $(\mathrm{C}, \mathrm{D})$. 


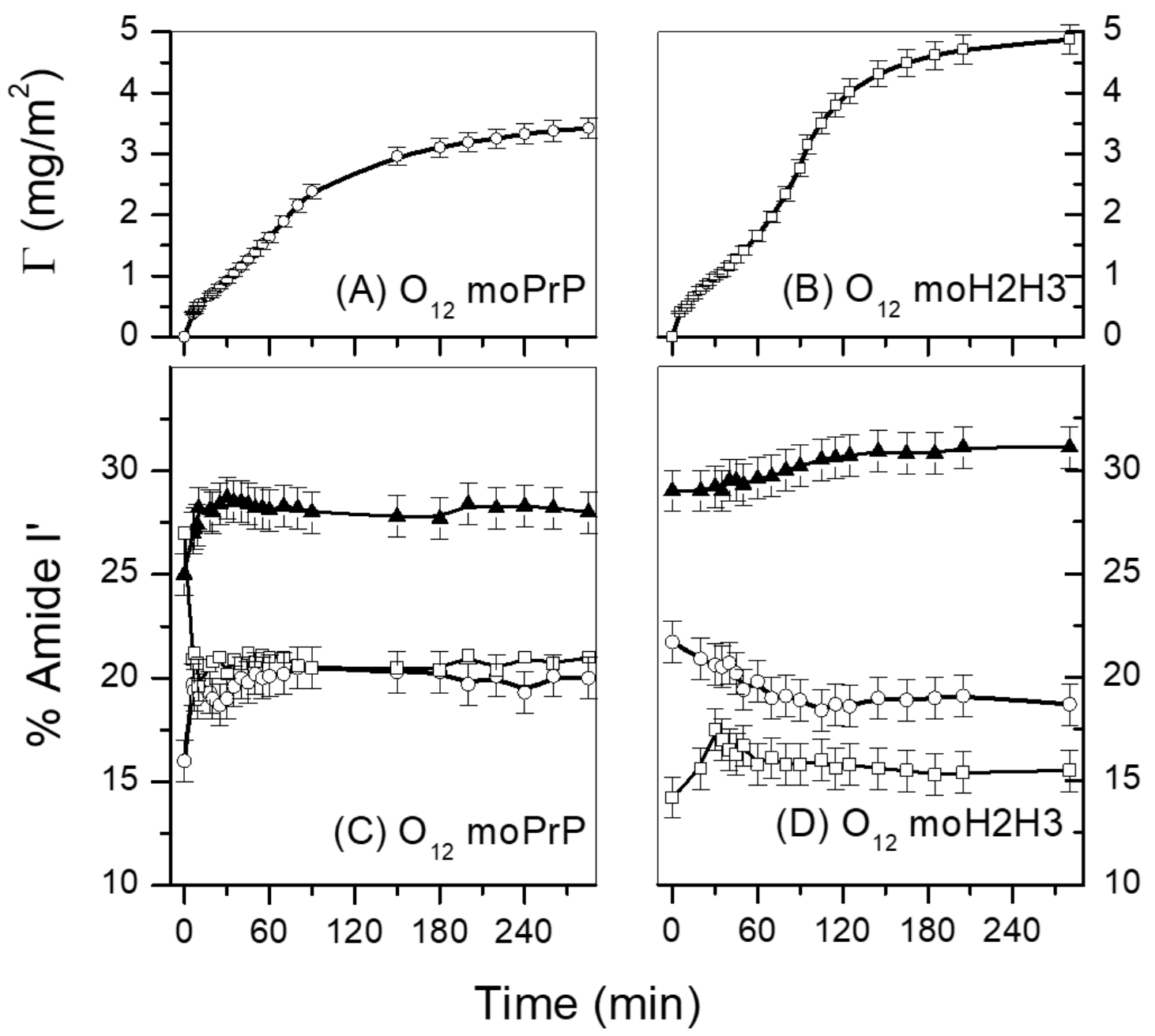

Figure 7: Adsorbed protein amount $(\Gamma)$ onto supported DOPC/DOPS bilayer for the $\mathrm{O}_{12} \mathrm{moPrP}$ at a bulk concentration of $3 \mu \mathrm{M}(\mathrm{A})$ and $\mathrm{O}_{12} \mathrm{moH} 2 \mathrm{H} 3$ at $5 \mu \mathrm{M}$ equivalent monomer concentration (B). The results are presented as the mean \pm SD of two independent experiments. The change in protein secondary structure monitored with time for moPrP oligomers (C) with the \% of the infrared component band area at $1622 \mathrm{~cm}^{-1}$ (triangle), at $1648 \mathrm{~cm}^{-1}$ (open circle), and at $1665 \mathrm{~cm}^{-1}$ (open square); for $\mathrm{H} 2 \mathrm{H} 3$ oligomers (D) with the component bands at $1620 \mathrm{~cm}^{-1}$ (triangle), at $1651 \mathrm{~cm}^{-1}$ (open circle), and at $1665 \mathrm{~cm}^{-1}$ (open square). The $\%$ Amide I' is for one representative experiment. The error bars are standard errors and are shown except for sake of clarity. 


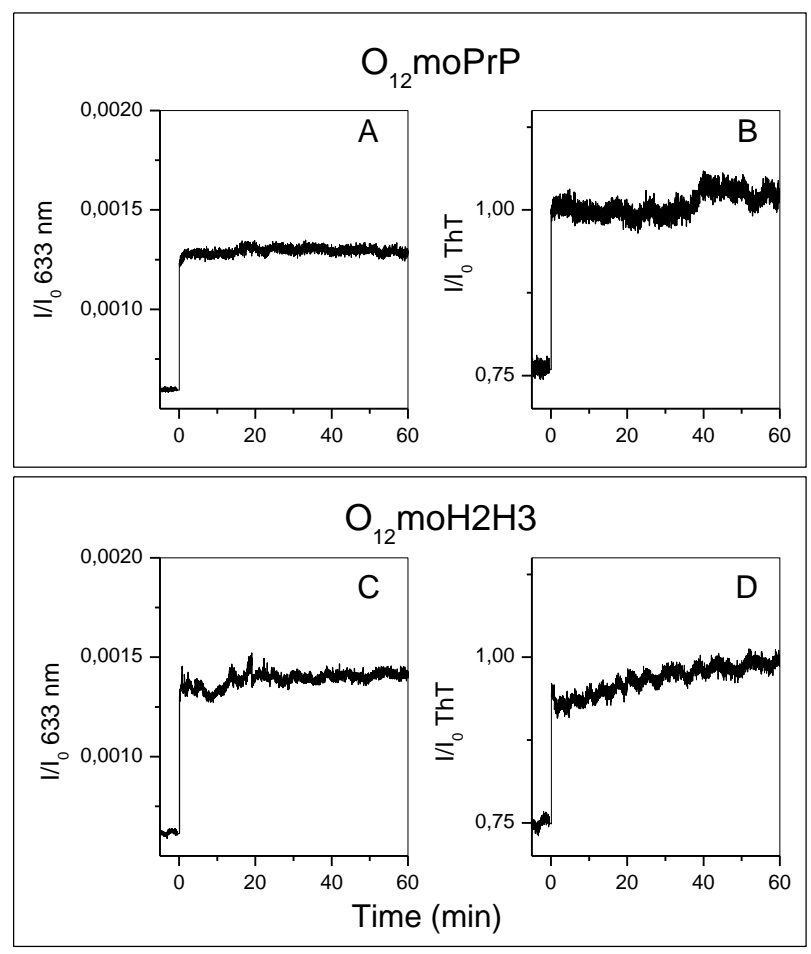

Figure 8: SLS (left) and ThT binding (right) experiments for oligomers of the full length moPrP at a concentration of $2 \mu \mathrm{M}$ in contact with DOPC/DOPS liposomes at $250 \mu \mathrm{M}$ at time 0 (A, B) compared to the corresponding experiments for the $\mathrm{O}_{12} \mathrm{moH} 2 \mathrm{H} 3$ at a concentration of $5 \mu \mathrm{M}(\mathrm{C}, \mathrm{D})$. 


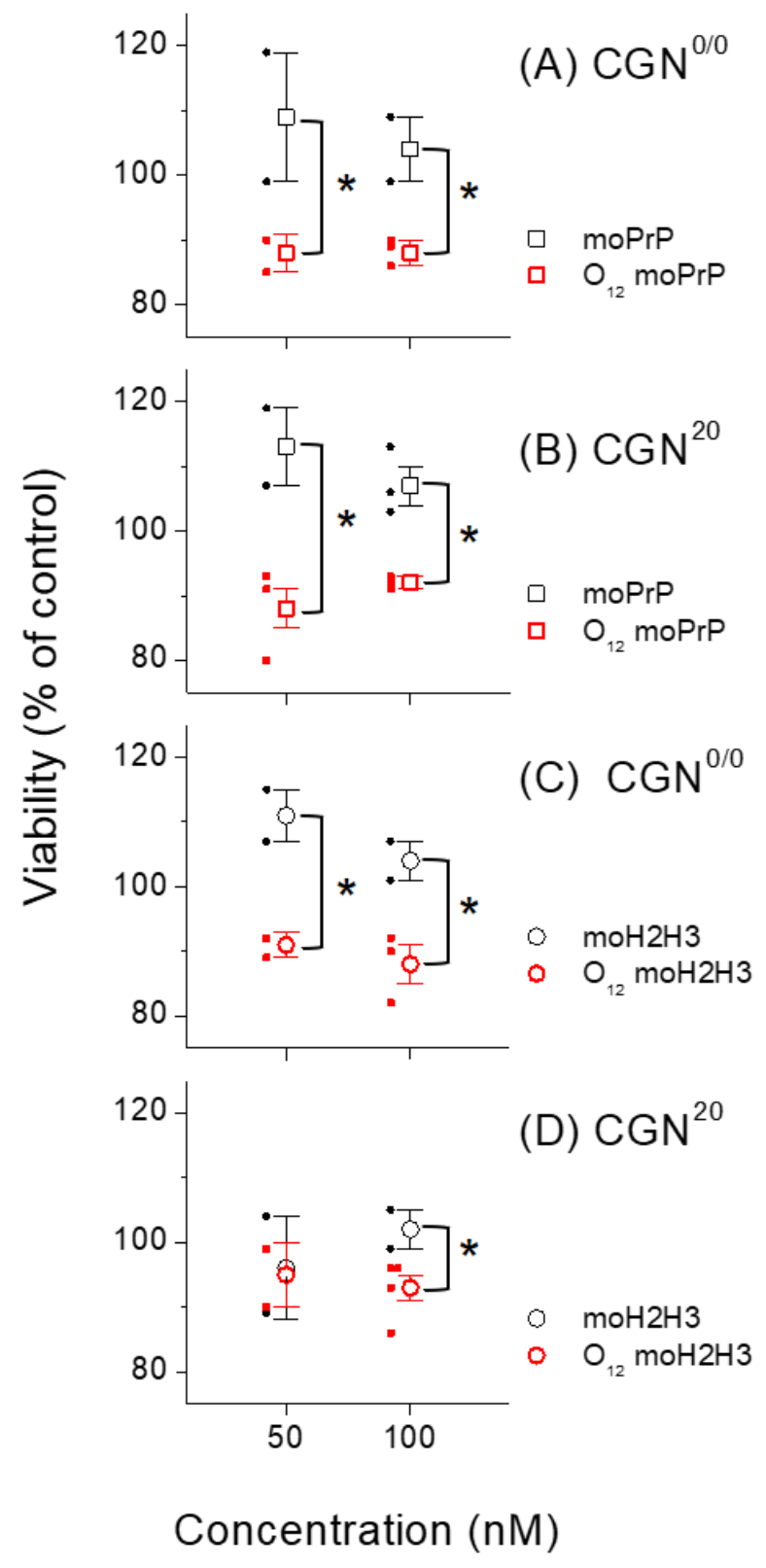

Figure 9: Neuronal survival after addition of full length mouse PrP monomers (A, B, black square), mouse $\mathrm{H} 2 \mathrm{H} 3$ monomers (C, D, black circle), full length mouse PrP oligomers (A, B, red square) and mouse $\mathrm{H} 2 \mathrm{H} 3$ oligomers $\left(\mathrm{C}, \mathrm{D}\right.$, red circle) on primary cultured neurons devoid of $\operatorname{PrP}^{\mathrm{C}}\left(\mathrm{A}, \mathrm{C}, \mathrm{CGN}^{0 / 0}\right)$ and on neurons expressing $\operatorname{moPrP}^{\mathrm{C}}\left(\mathrm{B}, \mathrm{D}, \mathrm{CGN}^{20}\right)$. Neuronal survival is expressed as a percentage of total living neurons (NeuN-positive cells) in mock-treated cultures. The small dots are data points obtained for independent experiments and the large dots indicate the data mean. The error bars represent standard errors of the mean. * indicates when survival statistically decreased $(\mathrm{p}<0.05$, Mann-Whitney U-test). 
(A) Pore formation at high concentration

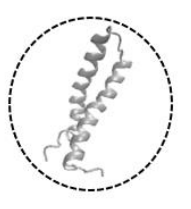

$$
\mathrm{D}_{\mathrm{h}}=2 \mathrm{~nm}
$$

Net charge -1

(C) Undefined permeation structures

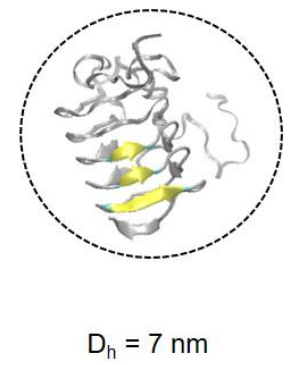

Net charge -12
(B) No perturbation

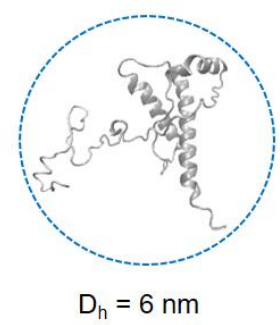

Net charge +9

(D) Pore formation

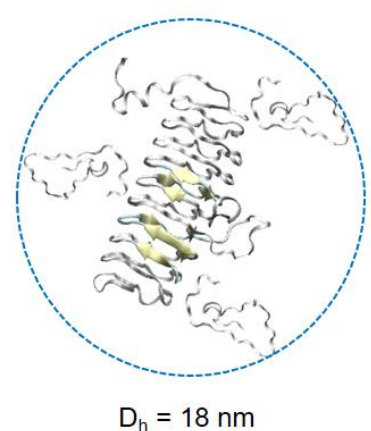

Net charge +108

Scheme 1: Schematic representation of the different constructs under study and their effect on lipid membranes: (A) mouse H2H3 monomer, (B) full length mouse PrP monomer, (C) mouse H2H3 oligomer and (D) full length mouse PrP oligomer. The structures for oligomers are presented for an illustrative purpose and $\beta$-sheets are indicated in yellow. Z-average hydrodynamic diameters are determined at $\mathrm{pH} 7$ in mops buffer. Net charge of the constructs is indicated at $\mathrm{pH} 7$. 
(A)

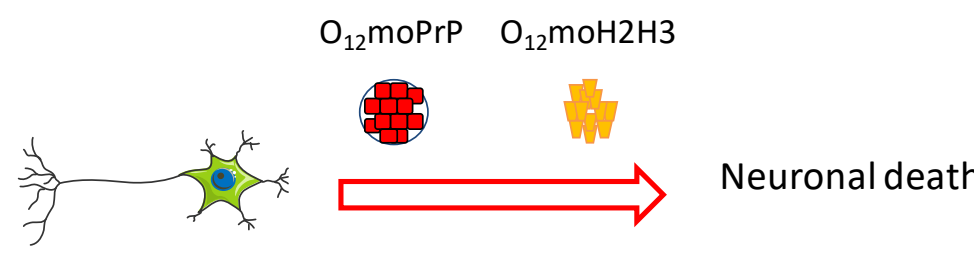

(B)
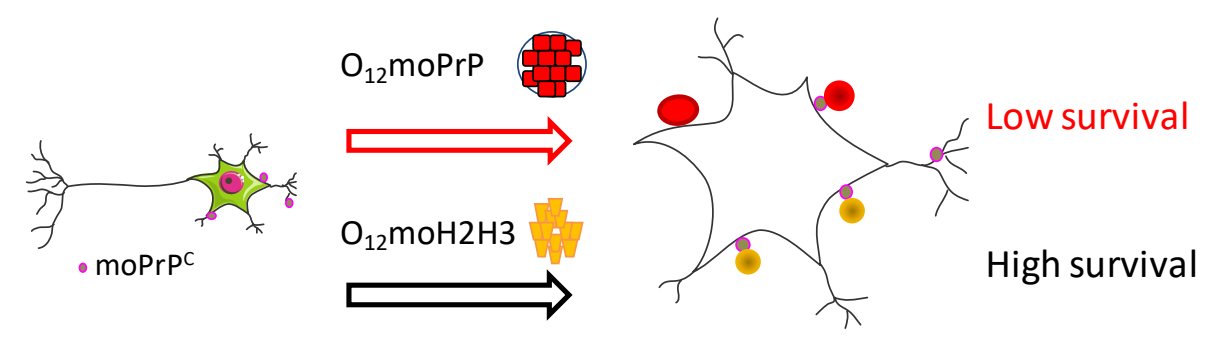

Scheme 2: Models for the neurotoxic effects of PrP oligomers: (A) Full length PrP oligomers or from the $\mathrm{H} 2 \mathrm{H} 3$ sequence are toxic to neurons devoid of $\operatorname{PrP}^{\mathrm{C}}\left(\mathrm{CGN}^{0 / 0}\right)$, in favour of a lipid mediated toxicity. Both $\beta$-sheeted oligomers cause ion currents in lipid model membranes. (B) For $\mathrm{CGN}^{20}$, the full length $\mathrm{PrP}$ oligomers entail low survival of neurons whereas the oligomers from $\mathrm{H} 2 \mathrm{H} 3$ sequence produce high survival in presence of $\mathrm{PrP}^{\mathrm{C}}$. The competition between the bindings of oligomers to $\operatorname{PrP}^{\mathrm{C}}$ or to lipid membrane results in more or less toxic effect. In presence of the cellular $\operatorname{PrP}^{\mathrm{C}}$, neurotoxicity is mediated by different $\mathrm{PrP}^{\mathrm{C}}$-oligomers complexes having distinct protective role. 
Supplemental Information

Conformation-dependent membrane permeabilization by neurotoxic PrP oligomers: the role of the $\mathrm{H} 2 \mathrm{H} 3$ oligomerization domain.

\section{Cécile Huin ${ }^{1,2}$, Sabrina Cronier ${ }^{3}$, Philippe Guégan ${ }^{1}$, Vincent Beringue ${ }^{3}$, Human}

\section{Rezaei $^{3}$, Sylvie Noinville ${ }^{3,4}$,}

From ${ }^{1}$ Sorbonne Université, CNRS, Institut Parisien de Chimie Moléculaire, Equipe Chimie des Polymères, 4 place Jussieu, F-75005 Paris, France, ${ }^{2}$ University of Evry, F-91025 Evry, France, ${ }^{3}$ UR892, Virologie et Immunologie Moléculaires, Institut National de la Recherche Agronomique (INRA), Jouy-en-Josas, France. And ${ }^{4}$ Sorbonne Universités, UPMC Univ Paris 06, CNRS, UMR8233, MONARIS, Université Pierre et Marie Curie, Paris, France. 
Table S1: Secondary structure contents (in \%) of PrP monomers and oligomers either in solution or in contact with DOPC/DOPS bilayers after the given time of contact from IR decomposition analysis.

\begin{tabular}{|c|c|c|c|c|c|c|c|}
\hline \multirow{3}{*}{$\begin{array}{l}\text { Wavenumber } \\
\qquad\left(\mathrm{cm}^{-1}\right)\end{array}$} & \multicolumn{7}{|c|}{ Monomers } \\
\hline & $1616^{\text {(a) }}$ & 1630 & $\begin{array}{c}1635 \text { or } \\
1640\end{array}$ & \multicolumn{2}{|c|}{1651} & 1665 & $\begin{array}{l}1671- \\
1682\end{array}$ \\
\hline & $\begin{array}{c}\text { Intermolecular } \\
\beta \text {-sheet }\end{array}$ & $\begin{array}{c}\text { Intramolecular } \\
\beta \text {-sheet }\end{array}$ & Random & \multicolumn{2}{|c|}{$\begin{array}{c}\alpha- \\
\text { helices } \\
\text { in polar } \\
\text { domains }\end{array}$} & $\begin{array}{c}\alpha- \\
\text { helices } \\
\text { in apolar } \\
\text { domains }\end{array}$ & $\begin{array}{l}\text { Random } \\
\text { or } \beta- \\
\text { turn }\end{array}$ \\
\hline $\begin{array}{l}\text { moH2H3 } \\
\text { In solution }\end{array}$ & 7 & 0 & 18 & \multicolumn{2}{|c|}{53} & 13.5 & 8.5 \\
\hline $\begin{array}{c}\mathrm{moH} 2 \mathrm{H} 3 \\
+\mathrm{PC} / \mathrm{PS} \\
130 \mathrm{~min}\end{array}$ & 30 & 17 & 0 & \multicolumn{2}{|c|}{27} & 15 & 11 \\
\hline $\begin{array}{c}\text { moPrP } \\
\text { In solution }\end{array}$ & 7.5 & 15 & 17.5 & \multicolumn{2}{|c|}{31} & 14 & 15 \\
\hline $\begin{array}{c}\text { moPrP } \\
+ \text { PC/PS } \\
120 \mathrm{~min}\end{array}$ & 12 & 19 & 18 & \multicolumn{2}{|c|}{22} & 12 & 17 \\
\hline & \multicolumn{7}{|c|}{ Oligomers } \\
\hline $\begin{array}{c}\text { Wavenumber } \\
\left(\mathrm{cm}^{-1}\right)\end{array}$ & & & \multicolumn{2}{|c|}{$1648-1651$} & \multicolumn{2}{|c|}{$1662-1665$} & $1678-1681$ \\
\hline Assignment & $\begin{array}{c}\text { Intramolecular } \\
\beta \text {-sheet }\end{array}$ & $\begin{array}{c}\text { Intramolecular } \\
\beta \text {-sheet }\end{array}$ & \multicolumn{2}{|c|}{ Random } & \multicolumn{2}{|c|}{$\beta$-turn } & $\beta$-turn \\
\hline $\begin{array}{l}\mathrm{O}_{12} \mathrm{moH} 2 \mathrm{H} 3 \\
\text { In solution }\end{array}$ & 28 & 28 & \multicolumn{2}{|c|}{22} & \multicolumn{2}{|r|}{14} & 8 \\
\hline $\begin{array}{c}\mathrm{O}_{12} \mathrm{moH} 2 \mathrm{H} 3 \\
+\mathrm{PC} / \mathrm{PS} \\
280 \mathrm{~min}\end{array}$ & 31 & 26 & \multicolumn{2}{|c|}{18} & \multicolumn{2}{|r|}{16} & 9 \\
\hline $\begin{array}{l}\mathrm{O}_{12} \mathrm{moPrP} \\
\text { In solution }\end{array}$ & 25 & 22 & \multicolumn{2}{|c|}{16} & \multicolumn{2}{|r|}{27} & 10 \\
\hline $\begin{array}{l}\mathrm{O}_{12} \mathrm{moPrP} \\
+\mathrm{PC} / \mathrm{PS} \\
240 \mathrm{~min}\end{array}$ & 28 & 21 & \multicolumn{2}{|c|}{19} & \multicolumn{2}{|r|}{21} & 10 \\
\hline
\end{tabular}

(a) In solution the band at $1616 \mathrm{~cm}^{-1}$ is assigned to the $\mathrm{C}=\mathrm{C}$ stretching mode of the aromatic residues. The component band at $1616 \mathrm{~cm}^{-1}$ could also be attributable to the in-phase vibration of the anti-parallel $\beta$-sheets, which is accompanied by the concomitant appearance of the outof-phase stretching band at $1685 \mathrm{~cm}^{-1}$ of minor intensity (1). The later minor component overlaps with components attributed to loops and turns at around $1680 \mathrm{~cm}^{-1}$. Noticeably, the component band at $1616 \mathrm{~cm}^{-1}$ is assigned to extended intermolecular $\beta$-sheets and corresponds to amyloid structures (2).

(b) The component band at $1620-1622 \mathrm{~cm}^{-1}$ observed in the IR spectra of soluble oligomers is assigned to intramolecular $\beta$-structure but with stronger hydrogen bonds than the component 
appearing at $1630-1638 \mathrm{~cm}^{-1}$. The component band at $1630-1638 \mathrm{~cm}^{-1}$ is generally assigned to intramolecular $\beta$-sheets in parallel conformation (3). The component band at $1620-1622 \mathrm{~cm}^{-1}$ is also observed in the IR spectra of purified prion fibers with no coupling with a highwavenumber component band (4), whereas other amyloid fibrils exhibit infrared bands assigned to antiparallel $\beta$-sheets with a clear correlation between major and minor components of the corresponding vibrational modes (5). The intensity ratio between the high (1678-1681) and low (1620-1622) wavenumber components calculated from spectral decomposition is 0.38 and 0.24 , respectively for full length moPrP and moH2H3 oligomers (Fig S3), which would indicate an arrangement of $\beta$-strands in an anti-parallel conformation if we make the assumption of the coupling between these two IR components $(3,5)$. 


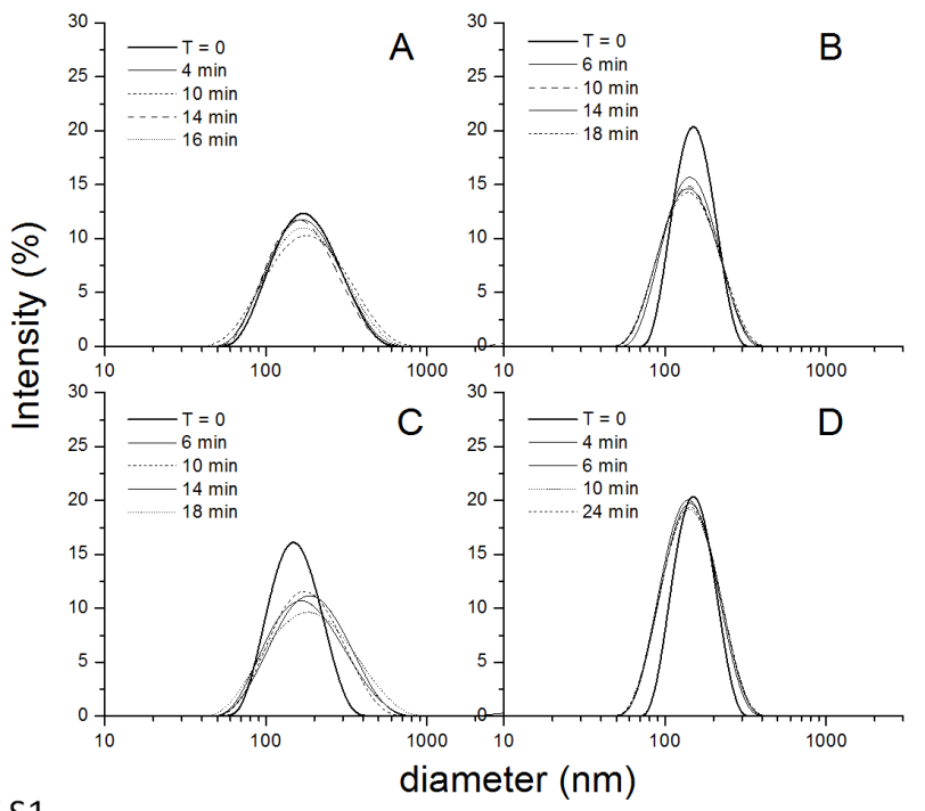

FIGURE S1

Figure S1. DLS measurements of liposomes DOPC/DOPS at $125 \mu \mathrm{M}(*)$ in interaction with monomeric $\mathrm{moH} 2 \mathrm{H} 3$ at a concentration of $1 \mu \mathrm{M}(\mathrm{A})$ and of $300 \mathrm{nM}$ (B) corresponding to a $\mathrm{L} / \mathrm{P}$ of $62.5 / 1$ and 420/1 respectively, compared to the corresponding addition of the oligomer at a concentration of $2 \mu \mathrm{M}(\mathrm{C})$ and of $500 \mathrm{nM}$ (D), corresponding to a L/P of 62.5/1 and 250/1 respectively. The plain line $(\mathrm{T}=0)$ corresponds to the size distribution of liposomes alone. (*) except for A where the concentration in liposomes was $62.5 \mu \mathrm{M}$. 


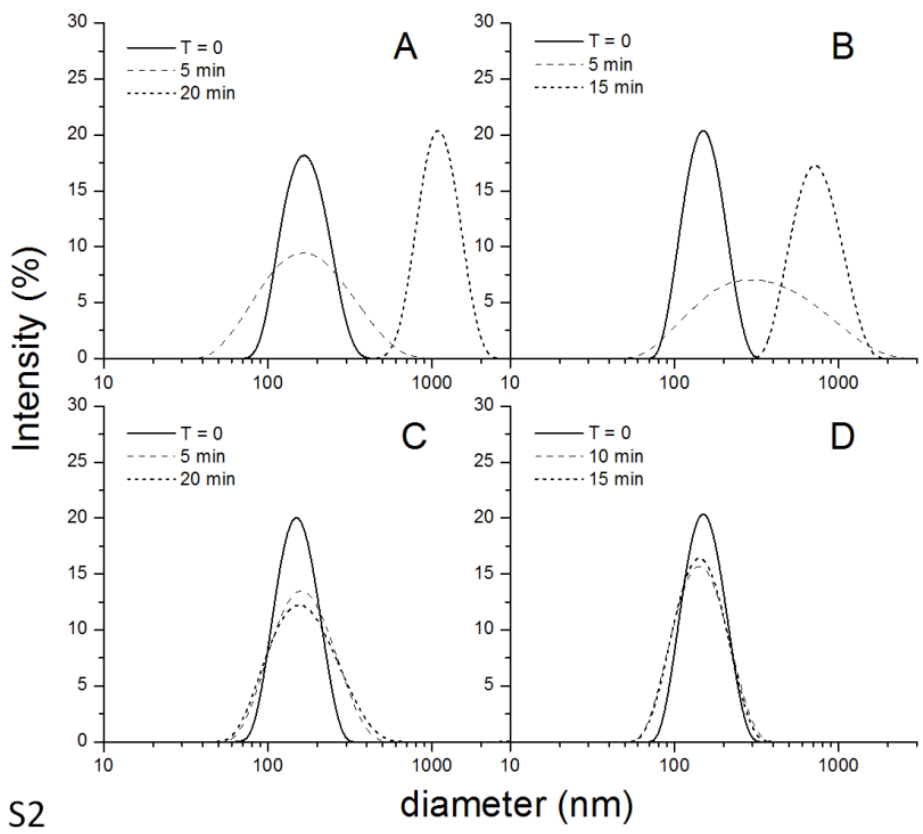

Figure S2. DLS measurements of liposomes DOPC/DOPS at $125 \mu \mathrm{M}$ in interaction with monomeric moPrP at a concentration of $6 \mu \mathrm{M}(\mathrm{A})$ and of $500 \mathrm{nM}(\mathrm{B})$ corresponding to a $\mathrm{L} / \mathrm{P}$ of $21 / 1$ and 250/1 respectively, compared to the corresponding addition of the oligomer at a concentration of $2 \mu \mathrm{M}(\mathrm{C})$ and of $500 \mathrm{nM}(\mathrm{D})$, corresponding to a $\mathrm{L} / \mathrm{P}$ of $62.51 / 1$ and 250/1 respectively. The plain line $(\mathrm{T}=0)$ corresponds to the size distribution of liposomes alone. 
(A) in solution
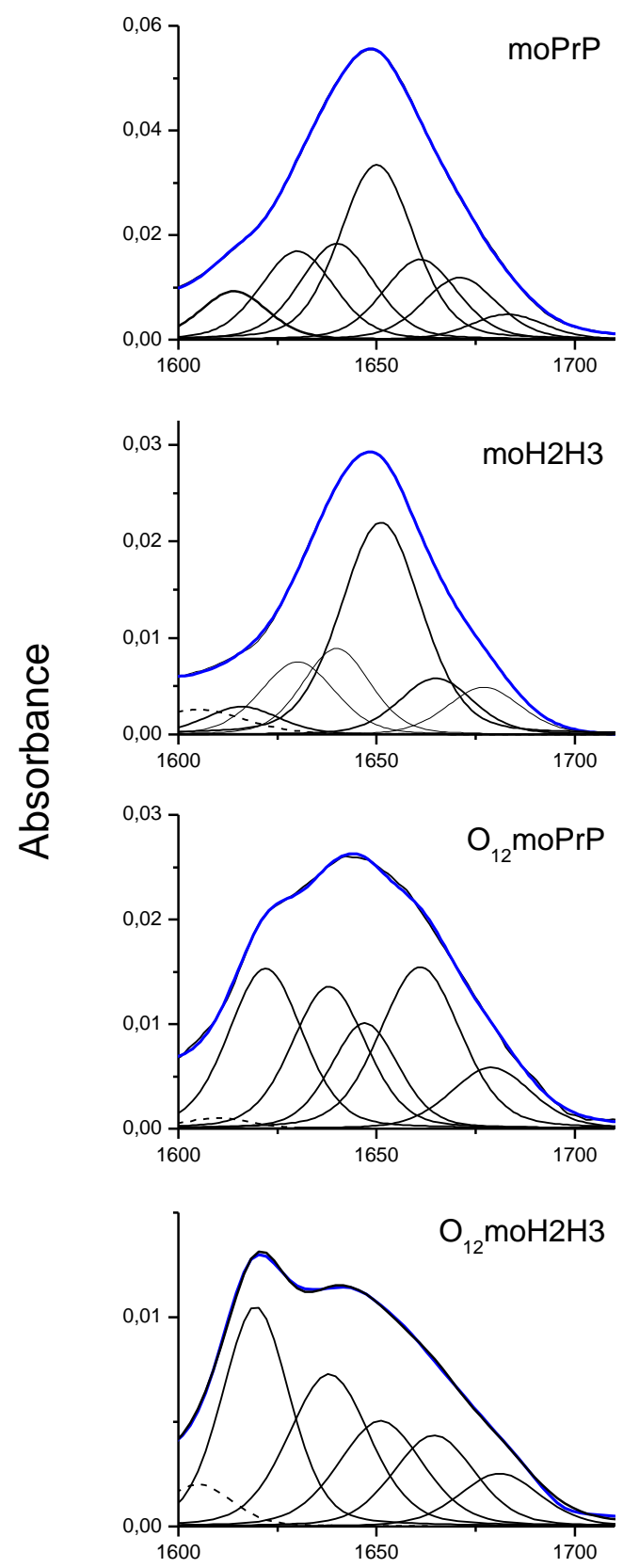

(B) in contact with PC/PS
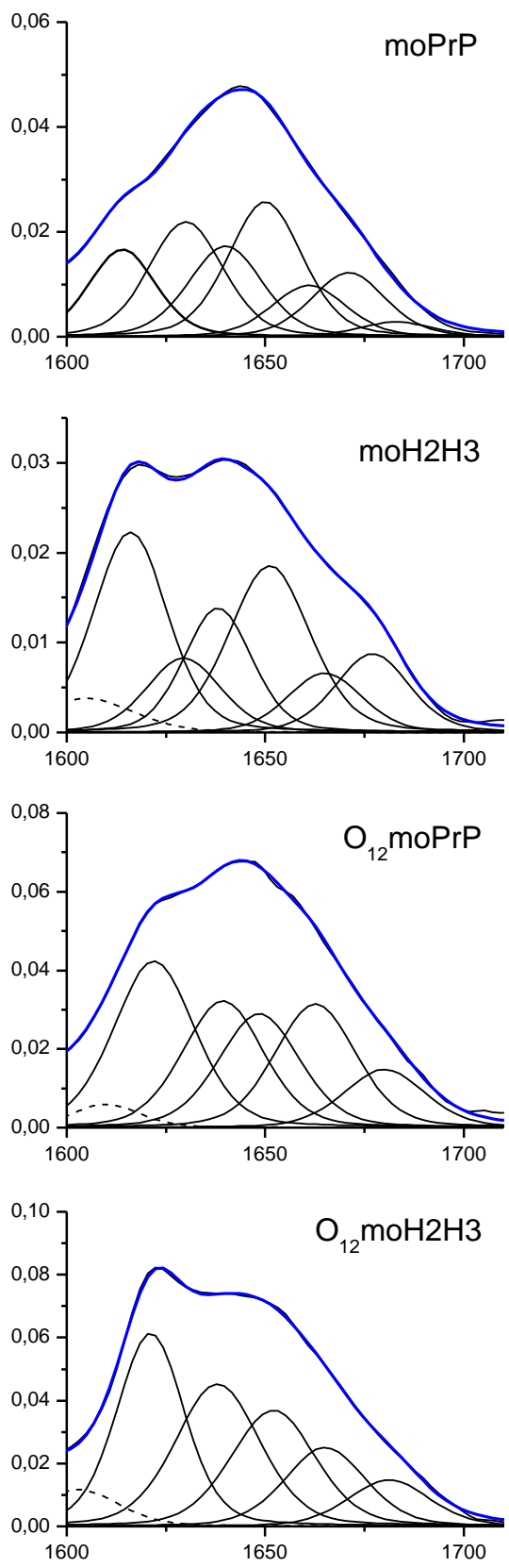

Wavenumber $\left(\mathrm{cm}^{-1}\right)$

Figure S3: Transmission and ATR-corrected spectra in the Amide I' band region and results of curve fitting procedure for secondary structural analysis of the different protein constructs at $\mathrm{pD} 6.5$ (A) in solution, from the top to bottom for monomeric moPrP at $175 \mu \mathrm{M}$, monomeric moH2H3 at $245 \mu \mathrm{M}$, for $\mathrm{O}_{12} \mathrm{moPrP}$ at $85 \mu \mathrm{M}$ with a $50 \mu \mathrm{m}$ optical path and for $\mathrm{O}_{12} \mathrm{moH} 2 \mathrm{H} 3$ at $72 \mu \mathrm{M}$ with a $100 \mu \mathrm{m}$ optical path; and (B) in contact with the DOPC/DOPS bilayer, from the top to bottom for monomeric moPrP at $5 \mu \mathrm{M}$ after $240 \mathrm{~min}$, for monomeric $\mathrm{moH} 2 \mathrm{H} 3$ at $15 \mu \mathrm{M}$ after $130 \mathrm{~min}$, for $\mathrm{O}_{12} \mathrm{moPrP}$ at $3 \mu \mathrm{M}$ after 240 min and for $\mathrm{O}_{12} \mathrm{moH} 2 \mathrm{H} 3$ at $5 \mu \mathrm{M}$ after $280 \mathrm{~min}$. The dashed lines correspond to the component band attributable to the $\mathrm{C}=\mathrm{C}$ stretching mode of aromatic side-chains. 
(A) in solution
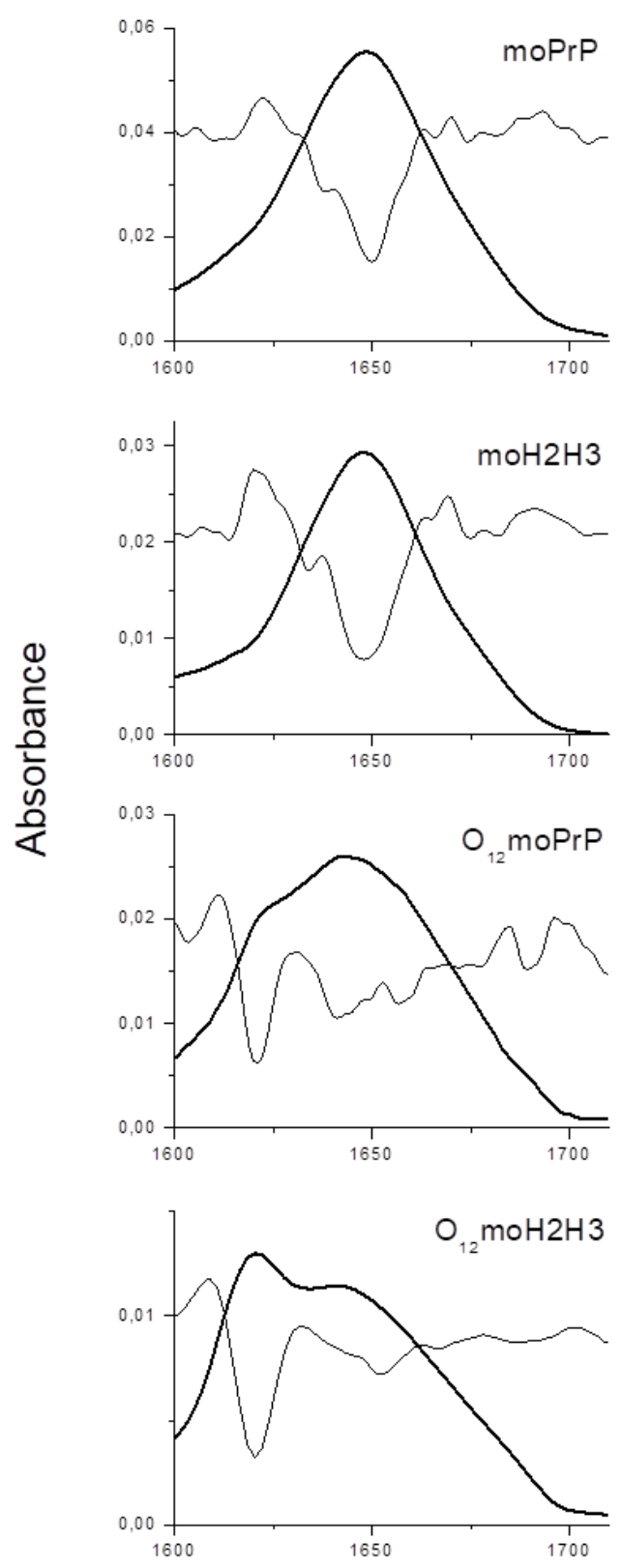

(B) in contact with PC/PS
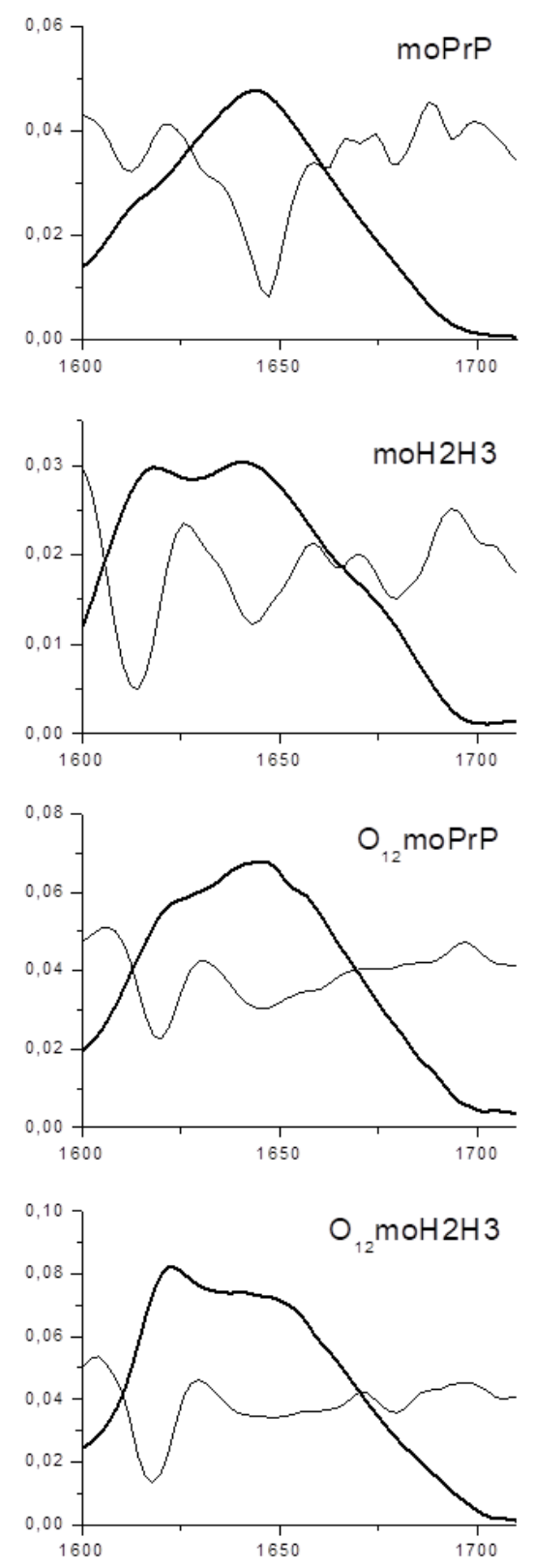

\section{Wavenumber $\left(\mathrm{cm}^{-1}\right)$}

Figure S3-bis: Transmission and ATR-corrected spectra in the Amide I' band region and second derivative spectra of the different protein constructs at $\mathrm{pD} 6.5$ (A) in solution, from the top to bottom for monomeric moPrP at $175 \mu \mathrm{M}$, monomeric $\mathrm{moH} 2 \mathrm{H} 3$ at $245 \mu \mathrm{M}$, for $\mathrm{O}_{12} \mathrm{moPrP}$ at $85 \mu \mathrm{M}$ with a 50 $\mu \mathrm{m}$ optical path and for $\mathrm{O}_{12} \mathrm{moH} 2 \mathrm{H} 3$ at $72 \mu \mathrm{M}$ with a $100 \mu \mathrm{m}$ optical path; and (B) in contact with the DOPC/DOPS bilayer, from the top to bottom for monomeric moPrP at $5 \mu \mathrm{M}$ after $240 \mathrm{~min}$, for

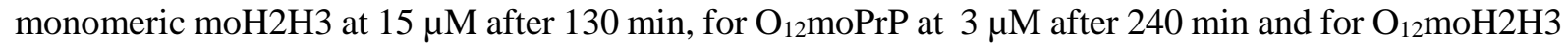
at $5 \mu \mathrm{M}$ after $280 \mathrm{~min}$. 


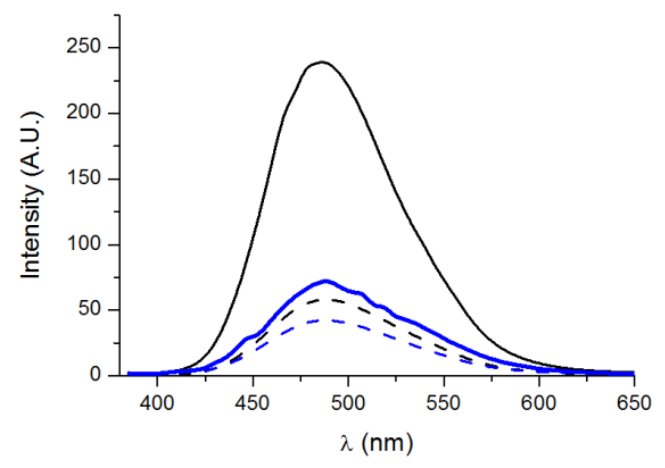

Figure S4. ANS fluorescence probing the relative exposures of hydrophobic clusters of $\mathrm{O}_{12} \mathrm{moPrP}$ (black) and $\mathrm{O}_{12} \mathrm{moH} 2 \mathrm{H} 3$ (blue) to their respective monomer (dashed lines). For each species the concentration was adjusted to $10 \mu \mathrm{M}$ in monomer equivalents at pH6.2.

ANS-binding experiments_ 8-anilino-1-naphthalene sulfonic acid (ANS) fluorescence measurements were performed at $20^{\circ} \mathrm{C}$ on a Jasco 6200 spectrofluorimeter with a $0.5 \mathrm{~mm} \times 10 \mathrm{~mm}$ optical path-length cuvette. The concentration was adjusted to $10 \mu \mathrm{M}$ for each species (in terms of monomer concentration) before incubation with $160 \mu \mathrm{M}$ ANS. Excitation was at $372 \mathrm{~nm}$ and each emission spectrum (from $400 \mathrm{~nm}$ to $650 \mathrm{~nm}$ ) was the average of the scans.

References:

(1) Miyazawa, T., Blout, E.R. (1961) The infrared spectra of polypeptides in various conformations: amide I and II bands. J. Am. Chem. Soc. 83, 712-719

(2) G. Zandomeneghi, M.R. Krebs, M.G. McCammon, M. Fandrich, FTIR reveals structural differences between native beta-sheet proteins and amyloid fibrils, Protein Sci., 13 (2004) 33143321.https://doi.org/10.1110/ps.041024904

(3) R. Sarroukh, E. Goormaghtigh, J.-M. Ruysschaert, V. Raussens, ATR-FTIR: A rejuvenated tool to investigate amyloid proteins, Biochim. Biophys. Acta Biomembr., 1828 (2013) 23282338.https://doi.org/10.1016/j.bbamem.2013.04.012

(4) J. Torrent, D. Martin, S. Noinville, Y. Yin, M. Doumic, M. Moudjou, V. Beringue, H. Rezaei, Pressure Reveals Unique Conformational Features in Prion Protein Fibril Diversity, Scientific reports, 9 (2019) 2802.10.1038/s41598-019-39261-8

(5) M.S. Celej, R. Sarroukh, E. Goormaghtigh, G.D. Fidelio, J.M. Ruysschaert, V. Raussens, Toxic prefibrillar alpha-synuclein amyloid oligomers adopt a distinctive antiparallel beta-sheet structure, Biochemical Journal, 443 (2012) 719-726 